\title{
Radio-millimetre investigation of galactic infrared dark clouds ${ }^{\star}$
}

\author{
D. Teyssier, P. Hennebelle, and M. Pérault
}

\begin{abstract}
Laboratoire de radioastronomie millimétrique, URA 336 du CNRS, École normale supérieure et Observatoire de Paris, 24 rue Lhomond, 75231 Paris Cedex 05, France
\end{abstract}

Received 29 December 2000 / Accepted 13 November 2001

\begin{abstract}
We present follow-up observations of the mid-Infrared dark clouds selected from the ISOGAL inner Galaxy sample. On-the-fly maps of ${ }^{13} \mathrm{CO}, \mathrm{C}^{18} \mathrm{O}$ and the $1.2 \mathrm{~mm}$ continuum emission were conducted at the IRAM 30-m telescope, showing spectacular correlation with the mid-IR absorption. The dark clouds are distributed as far as the prominent molecular ring at a distance of 3 to $7 \mathrm{kpc}$ from the Sun. The clouds exhibit shapes ranging from globules to thin filaments down to $\lesssim 1 \mathrm{pc}$ in size. The on-the-fly images obtained in ${ }^{13} \mathrm{CO}$ and $\mathrm{C}^{18} \mathrm{O}$ confirmed that the cores are dense, compact molecular emitters, significantly more massive than local dark clouds (more than $1000 M_{\odot}$ ) and lie within low activity Giant Molecular Clouds (GMC's). Ratios of the emission in the $J=(2-1)$ and $(1-0)$ transitions of ${ }^{13} \mathrm{CO}$ and $\mathrm{C}^{18} \mathrm{O}$ show a remarkable uniformity within each cloud, with a significant portion of the sample represented well by a ratio of $0.67 \pm 0.12$. Preliminary analysis of temperature and density measurements reveals that most of the cores have densities above $10^{5} \mathrm{~cm}^{-3}$ and temperatures between 8 and $25 \mathrm{~K}$, these latter clouds being associated with young embedded stars. Despite the high extinction inferred from mid-IR $\left(A_{\mathrm{v}}>50\right.$, Hennebelle et al. 2001), the molecular lines are surprisingly weak, indicating likely depletion onto cold grains.
\end{abstract}

Key words. ISM: clouds - molecules - structure - radio continuum: ISM - radio lines: ISM

\section{Introduction}

Galactic dark clouds observed in the mid-Infrared were first surveyed by ISO (Pérault et al. 1996), and turn out to be the highly condensed parts of Giant Molecular Clouds (GMC's) kiloparsecs away from the Sun. The ISOGAL survey imaged $\sim 10 \%$ of the inner Galactic ridge, mostly towards relatively quiescent areas, in broad filters around 7 and $15 \mu \mathrm{m}$ (Omont et al. 1999). A systematic analysis of the ISOGAL plates (Hennebelle et al. 2001, hereafter Paper I) allowed extraction of a catalogue of about 450 objects, most of them located in the inner Galaxy. The features are associated with GMC's lying between 3 and $7 \mathrm{kpc}$ from us. In Paper I, we derived opacities at $15 \mu \mathrm{m}$ in the range 1 to 4 for a few selected objects, leading to column densities of the order of $10^{23} \mathrm{~cm}^{-2}$.

Similar findings have been reported by Egan et al. (1998) from the MSX (Midcourse Space Experiment) survey of the whole Galactic plane. They counted about 2000 IR dark clouds (IRDC's) located in the same distance range as the ISOGAL clouds and estimated extinctions at $8 \mu \mathrm{m}$ in excess of 2 . Detections of few clouds

\footnotetext{
Send offprint requests to: D. Teyssier,

e-mail: teyssier@lra.ens.fr

* Appendices A and B are only available in electronic form at http://www.edpsciences.org
}

at millimetre wavelengths (Carey et al. 1998) confirmed that these objects are dense $\left(n_{\mathrm{H}_{2}}>10^{5} \mathrm{~cm}^{-3}\right)$ and cold $(T<20 \mathrm{~K})$. The authors conclude that these clouds are pre-protostellar cores where no sign of star-formation has been detected so far. This analysis was recently refined using continuum detection at 850 and $450 \mu \mathrm{m}$ (Carey et al. 2000). The relatively high masses inferred from the submillimetre observations suggest a significant potential for stellar formation in these cores.

In the present paper we analyse spectroscopic and continuum follow-up observations of the ISOGAL dark features, conducted at the IRAM 30-m telescope. A sample of 13 objects has been mapped in several molecular tracers. A few characteristic physical parameters are inferred. The spatial resolution of these observations $\left(11^{\prime \prime}\right.$ at $\left.1.3 \mathrm{~mm}\right)$ opens the way to the analysis of the gas associated with the dense dust revealed by the mid-IR absorption at an intermediate spatial scale. Our main purpose is to compare the properties of our objects to those of the well-known local dark clouds. A subsequent study will provide an extensive analysis of temperature and density measurements and better assess the physico-chemical processes at work in the clouds (Teyssier et al. 2001b).

Section 2 presents the observational conditions and strategy. In Sect. 3 we describe the correlation between the millimetre emission and the IR absorption data. 
Table 1. Line parameters.

\begin{tabular}{lcrrr}
\hline \hline Species & Transitions & $\begin{array}{r}\nu_{0} \\
(\mathrm{GHz})\end{array}$ & $\begin{array}{r}\text { HPBW } \\
\left({ }^{\prime \prime}\right)\end{array}$ & $\begin{array}{r}T_{\text {sys }} \\
(\mathrm{K})\end{array}$ \\
\hline${ }^{13} \mathrm{CO}$ & $1 \rightarrow 0$ & 110.201353 & 22.5 & $150-250$ \\
& $2 \rightarrow 1$ & 220.398686 & 11.2 & $400-900$ \\
$\mathrm{C}^{18} \mathrm{O}$ & $1 \rightarrow 0$ & 109.782160 & 22.5 & $150-250$ \\
& $2 \rightarrow 1$ & 219.560319 & 11.3 & $400-900$ \\
$\mathrm{HC}_{3} \mathrm{~N}$ & $9 \rightarrow 8$ & 81.881468 & 30.2 & $130-250$ \\
& $10 \rightarrow 9$ & 90.978993 & 27.2 & $130-250$ \\
& $11 \rightarrow 10$ & 100.076389 & 24.7 & $130-250$ \\
$\mathrm{CH}_{3} \mathrm{CCH}$ & $5_{0} \rightarrow 4_{0}$ & 85.457300 & 28.9 & $130-250$ \\
& $60 \rightarrow 50$ & 102.547984 & 24.1 & $130-250$ \\
$\mathrm{HCO}^{+}$ & $1 \rightarrow 0$ & 89.188518 & 27.7 & $150-250$ \\
$\mathrm{HCN}$ & $1 \rightarrow 0$ & 88.631847 & 27.9 & $150-250$ \\
\hline
\end{tabular}

Note. $-\nu_{0}$ is the rest frequency of the line, HPBW is the ideal half power beam width given by $1.2 \lambda / D$ where $D$ is the telescope diameter and $\lambda$ the line wavelength, $T_{\mathrm{sys}}$ is the SSB system temperature.

The nature of the different objects is assessed and a detailed spatial and spectral analysis is introduced. Section 4 gives the physical properties of the clouds and their relation to the mid-IR opacities estimated in Paper I. Section 5 summarises our conclusions.

\section{Observations}

Observations of 13 IR dark clouds were conducted at the IRAM 30-m telescope between July 1998 and August 1999. Two summer runs were dedicated to spectroscopic observations, while continuum mapping at $1.2 \mathrm{~mm}$ was performed during winter time. Line and source parameters are listed in Tables 1 and 2.

\subsection{Spectroscopic observations}

Spectroscopic observations were performed during summertime under good to average weather conditions, in single-side band (SSB) mode, with receiver temperatures of about $90 \mathrm{~K}$ at $3 \mathrm{~mm}$ and $180 \mathrm{~K}$ at $1.3 \mathrm{~mm}$. The data were calibrated to the $T_{\mathrm{A}}^{*}$ scale using the chopper wheel method (Penzias \& Burrus 1973). Discussion on the final brightness temperature scale $T_{\mathrm{mb}}^{\prime}$ adopted for our data is presented in Appendix A.1. Using comparison with observations of line calibrators (Mauersberger et al. 1989), we believe our absolute calibration to be better than $20 \%$. The pointing accuracy was checked by repeated continuum scans across planets and strong quasars. The spectrometer was an autocorrelator set to a resolution of $80 \mathrm{kHz}$, yielding velocity channels of $0.24 \mathrm{~km} \mathrm{~s}^{-1}$ $\left(0.1 \mathrm{~km} \mathrm{~s}^{-1}\right)$ at $3 \mathrm{~mm}(1.3 \mathrm{~mm})$. Additional details on the technique used to correct for baseline spurious effects in the autocorrelator are given in Appendix A.2.

The maps were obtained with the Spectral Line Onthe-Fly technique (Ungerechts et al. 1999) with a scanning speed of $1^{\prime \prime} / \mathrm{s}$ (samples every $2 \mathrm{~s}$ ) and a cross-scan
Table 2. Source parameters.

\begin{tabular}{lccc}
\hline \hline Name & $\begin{array}{c}\mathrm{RA} \\
(\mathrm{J} 2000.0)\end{array}$ & $\begin{array}{c}\text { Dec } \\
(\mathrm{J} 2000.0)\end{array}$ & $\begin{array}{c}d^{(C)} \\
(\mathrm{kpc})\end{array}$ \\
\hline $\mathrm{DF}+04.36-0.06$ & $17: 55: 53.07$ & $-25: 13: 18.7$ & 3.5 \\
$\mathrm{DF}+09.86-0.04^{(A)}$ & $18: 07: 37.22$ & $-20: 25: 54.5$ & 2.8 \\
$\mathrm{DF}+15.05+0.09^{(A)}$ & $18: 17: 37.87$ & $-15: 48: 59.9$ & 3.1 \\
$\mathrm{DF}+18.56-0.15$ & $18: 25: 19.52$ & $-12: 49: 57.0$ & 4.0 \\
$\mathrm{DF}+18.79-0.03$ & $18: 25: 19.84$ & $-12: 34: 23.1$ & 3.6 \\
$\mathrm{DF}+25.90-0.17$ & $18: 39: 10.13$ & $-06: 19: 58.8$ & 5.5 \\
$\mathrm{DF}+30.23-0.20^{(B)}$ & $18: 47: 13.16$ & $-02: 29: 44.7$ & 6.7 \\
$\mathrm{DF}+30.31-0.28$ & $18: 47: 39.03$ & $-02: 27: 39.8$ & 6.3 \\
$\mathrm{DF}+30.36+0.11$ & $18: 46: 21.16$ & $-02: 14: 19.0$ & 5.9 \\
& & & $7.4^{(D)}$ \\
$\mathrm{DF}+30.36-0.27$ & $18: 47: 42.37$ & $-02: 24: 43.2$ & 6.9 \\
$\mathrm{DF}+31.03+0.27^{(B)}$ & $18: 47: 00.39$ & $-01: 34: 10.0$ & 4.9 \\
& & & 6.0 \\
$\mathrm{DF}+36.95+0.22$ & $18: 57: 59.51$ & $+03: 40: 33.3$ & 5.0 \\
$\mathrm{DF}+51.47+0.00^{(B)}$ & $19: 26: 12.74$ & $+16: 26: 12.6$ & $5.3^{(D)}$ \\
\hline
\end{tabular}

(A) Observed in April'99 (continuum).

(B) Observed both in April'99 and August'99.

(C) More than one value may be given in case several lines are detected on the line of sight.

$(D)$ Distance of the tangent point is assumed.

sampling of $6^{\prime \prime}$. We used two classes of reference positions. The targets were mapped using a close-by reference position that was then compared to a further one chosen from the Massachusetts-Stony Brook Galactic Plane CO Survey (Sanders et al. 1986) and estimated as sufficiently free of emission. Finally, whenever possible, map coverages in the orthogonal direction were achieved allowing use of the PLAIT algorithm developed by Emerson et al. (1988).

Maps of $3^{\prime} \times 3^{\prime}$ or $4^{\prime} \times 4^{\prime}$ were obtained for 7 of the fields and narrow bands of $0.5^{\prime} \times 3^{\prime}$ for the other ones. $\mathrm{HCO}^{+}$and $\mathrm{HCN} J=1-0$ lines were measured in parallel with ${ }^{13} \mathrm{CO}$ and $\mathrm{C}^{18} \mathrm{O}\left(\mathrm{HCO}^{+}\right.$and $\mathrm{HCN}$ data are not discussed here). Examples of integrated maps are given in Figs. 1 and 2. Noise levels (rms) reached are around $0.26 \mathrm{~K}(0.53 \mathrm{~K})$ at $3 \mathrm{~mm}(1.3 \mathrm{~mm})$ per regridded pixel and spectral resolution elements of $80 \mathrm{kHz}$. Three of the targets were observed in a second run in $\mathrm{HC}_{3} \mathrm{~N}$ and $\mathrm{CH}_{3} \mathrm{CCH}$ (see transitions in Table 1 ). $\mathrm{HC}_{3} \mathrm{~N}$ maps of $1.4^{\prime} \times 1.4^{\prime}$ were obtained to further allow for accurate comparison of lines at different frequencies by restoring all data to a common synthetic beam. Transitions of $\mathrm{CH}_{3} \mathrm{CCH}$ were observed in position switching, yielding a $20 \mathrm{mK}$ rms level per spectral resolution element.

\subsection{Continuum observations}

Five clouds were mapped using the MPIfR 37-channel bolometer array centred at $\sim 1.2 \mathrm{~mm}$ (Kreysa 1992; Kramer et al. 1998). We used the on-the-fly mode for continuum observations, consisting of dual-beam rasters with scanning velocities of $6^{\prime \prime} / \mathrm{s}$ or $8^{\prime \prime} / \mathrm{s}$. The spatial sampling interval in elevation was larger than generally used at the 


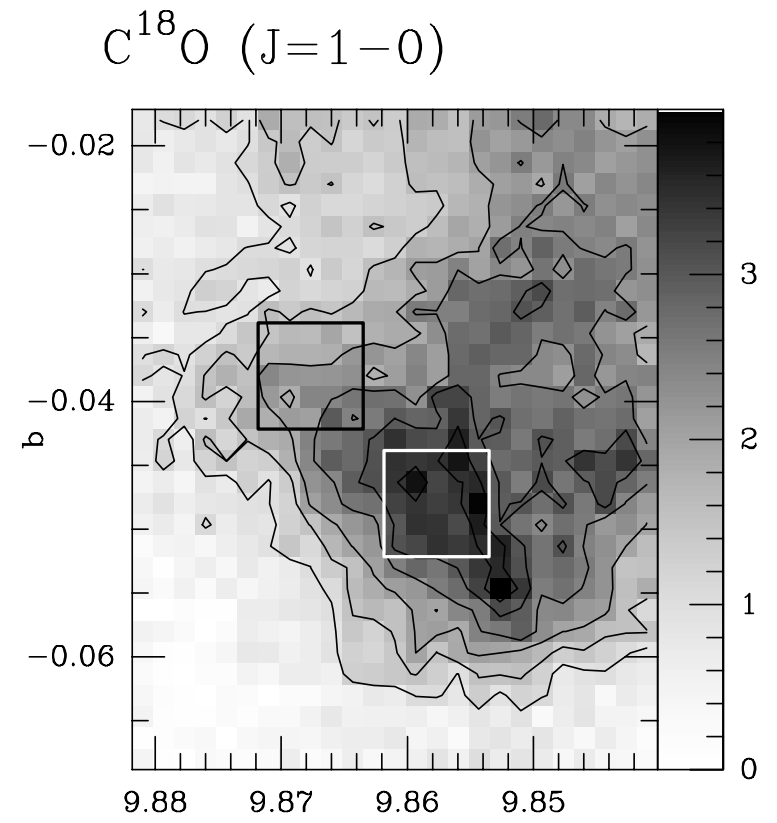

$$
\mathrm{C}^{18} \mathrm{O}(\mathrm{J}=2-1)
$$
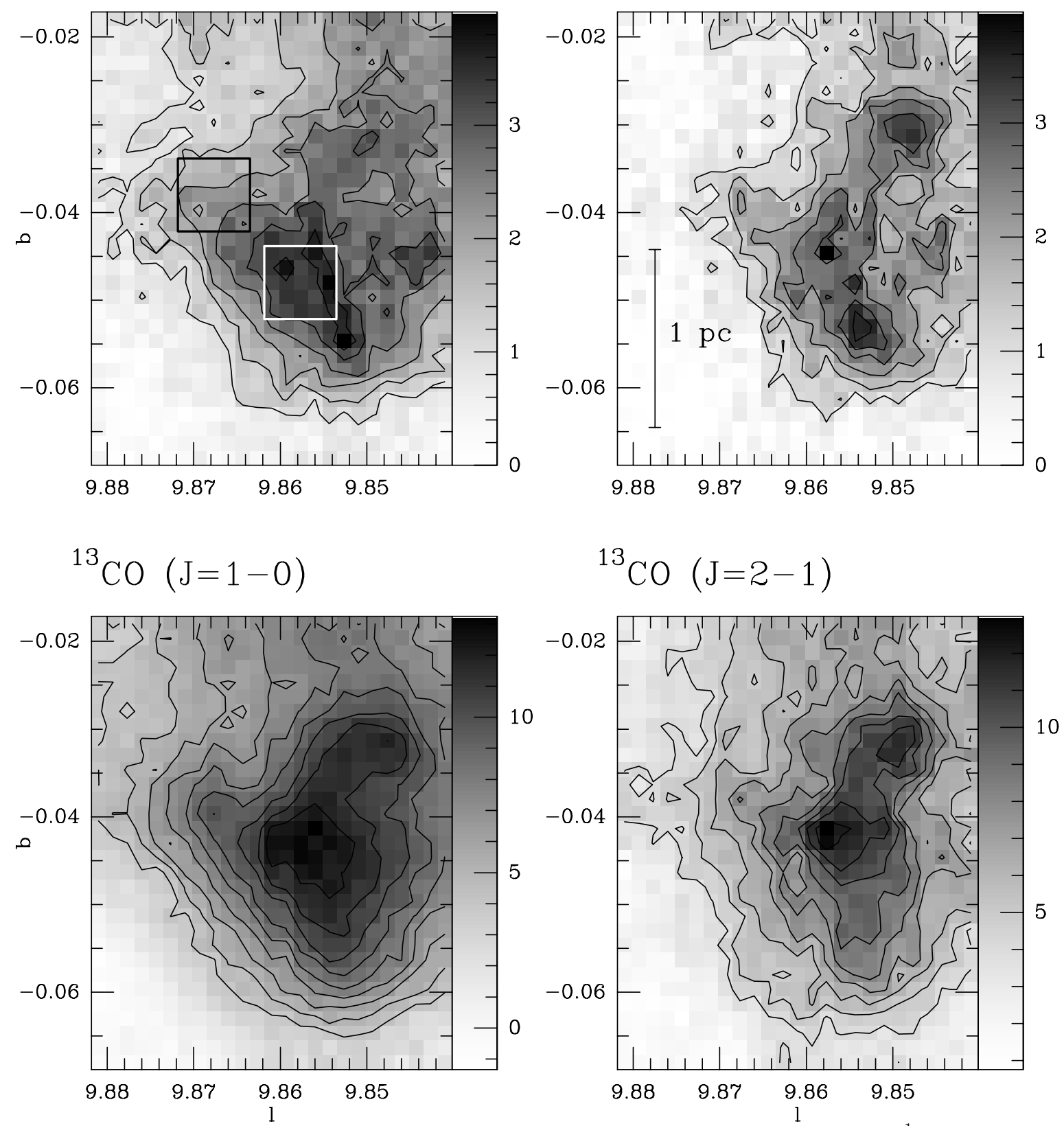

Fig. 1. Maps of CO isotopomers integrated emission for $\mathrm{DF}+09.86-0.04$. Contours are 1 to $4 \mathrm{~K} \mathrm{~km} \mathrm{~s}^{-1}$ by steps of 0.5 for $\mathrm{C}^{18} \mathrm{O}$ transitions and 4 to $12 \mathrm{~K} \mathrm{~km} \mathrm{~s}^{-1}$ by steps of 1 for ${ }^{13} \mathrm{CO}$ maps ( $T_{\mathrm{A}}^{*}$ scale). Velocity interval is $16-20 \mathrm{~km} \mathrm{~s}^{-1}$. The white box indicates the core position while the black one frames the envelope area used in the analysis.

$30-\mathrm{m}$ telescope. With a vertical offset of $24^{\prime \prime}$ (instead of $4-$ $\left.5^{\prime \prime}\right)$, individual detector maps are under-sampled but the co-added final map is fully sampled (Teyssier \& Sievers 1999). In a relatively short time (about $20 \mathrm{~min}$ ) we could cover areas of $7^{\prime} \times 6^{\prime}$ with homogeneous observing conditions and a small field curvature when re-projecting in the equatorial frame. All maps were repeated several times at different hour angles and with different wobbler throws $\left(46^{\prime \prime}, 56^{\prime \prime}\right.$ and $\left.78^{\prime \prime}\right)$ in order to allow the restoration of all spatial frequencies (see Emerson et al. 1995; Pierce-Price et al. 2001). This additional information, however, is not used by the IRAM data reduction software (NIC, Broguière et al. 1999) that we have used to derive the images presented here. A straightforward restoration algorithm (Emerson et al. 1979) is applied instead, followed by zero-order baseline substraction and a systematic skynoise removal. Figure 3 gives an example of two of these maps.

The beam size at $1.2 \mathrm{~mm}$ was measured to be $\sim 11^{\prime \prime}$ using Uranus. The calibration was achieved through regular on-the-fly and on-off observations on planets (Uranus and Mars). We estimated both relative and absolute calibration to be within $\sim 10 \%$. The zenith atmospheric optical 

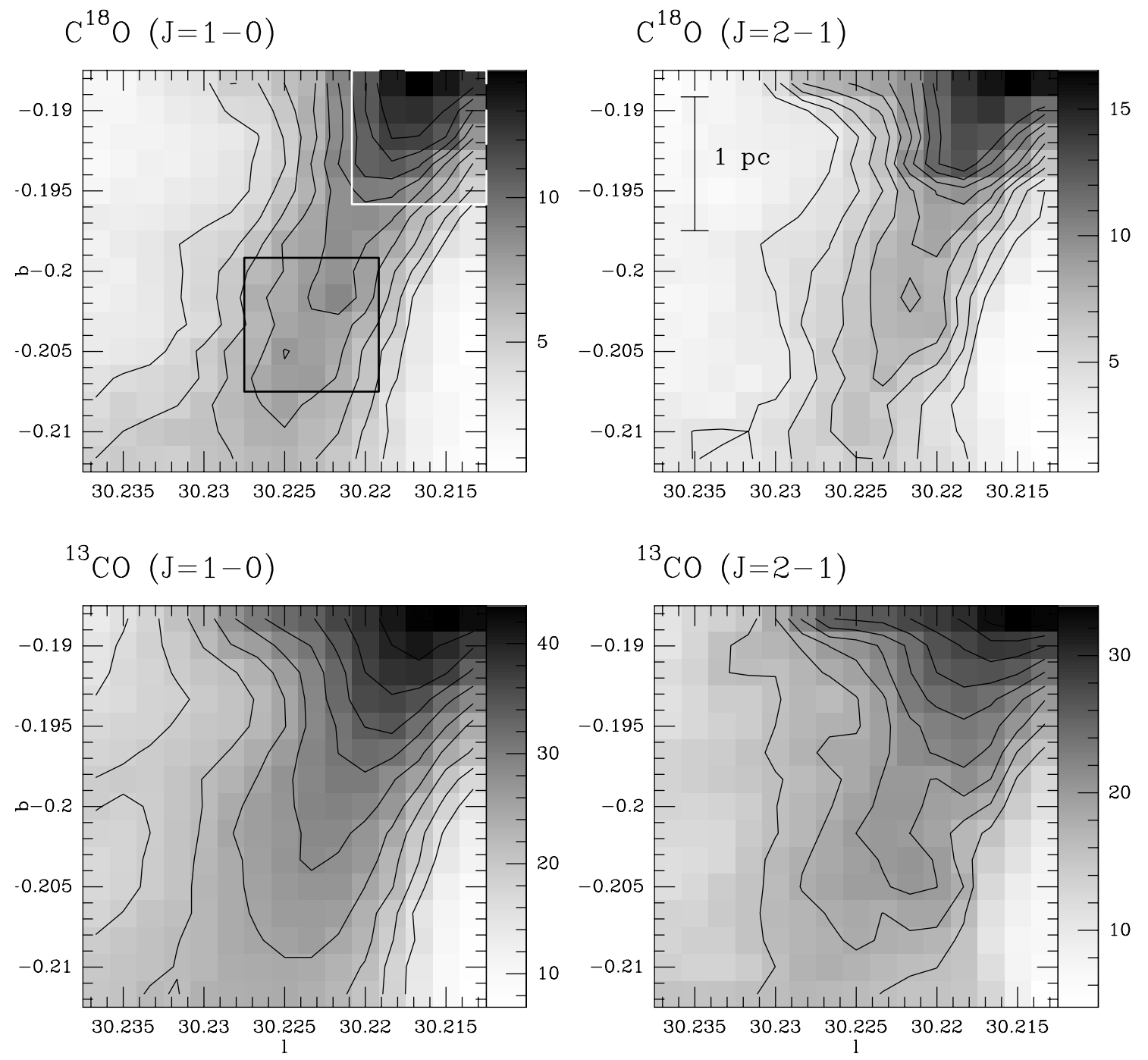

Fig. 2. Same as Fig. 1 for the central area of $\mathrm{DF}+30.23-0.20$. Contours are 4 to $12 \mathrm{~K} \mathrm{~km} \mathrm{~s}^{-1}$ by steps of 1 for $\mathrm{C}^{18} \mathrm{O}$ transitions, 16 to $35 \mathrm{~K} \mathrm{~km} \mathrm{~s}^{-1}$ by steps of 2 for ${ }^{13} \mathrm{CO}(J=2-1)$ and 16 to $45 \mathrm{~K} \mathrm{~km} \mathrm{~s}^{-1}$ by steps of 3 for ${ }^{13} \mathrm{CO}(J=1-0)\left(T_{\mathrm{A}}^{*}\right.$ scale). Velocity interval is $103-107 \mathrm{~km} \mathrm{~s}^{-1}$. The black box indicates the filament position while the white one frames the star edge area.

depth was found to be between $\sim 0.1$ and $\sim 0.3$, according to regular antenna tipping.

\section{Observational properties}

\subsection{Identification of the clouds and spatial distribution}

The infrared absorption features coincide remarkably with the $\mathrm{C}^{18} \mathrm{O}$ emission ridges (left and middle panels of Fig. 4), as well as with the continuum emission, although sometimes to a smaller extent (right hand panels of Fig. 4). In some of the clouds local peaks in the millimetre maps coincide with the mid-IR emission of embedded stars or stellar clusters seen by ISO. The identification of $\mathrm{OH}$ and $\mathrm{CH}_{3} \mathrm{OH}$ masers (Caswell et al. 1995, see Fig. 3) associated with these bright sources give additional evidence that stars may have formed recently.

Figures 3 and 4 illustrate such cases. For DF+09.860.04 , the embedded stars appear as two small black squares indicated by arrows in the infrared data (marked with white stars in the continuum map). For DF+30.230.20 , the stars themselves have not been mapped in CO, but are clearly seen as strong spots in continuum (white stars symbols). The dark filament turns to a bright filament in the mid-IR, while its millimetre emission is strongly reinforced around newly formed stars (Fig. 3).

Some of the clouds present several emission line components along the line of sight (e.g. DF $+30.36+0.11$ and $\mathrm{DF}+31.03+0.27$, which are the most distant clouds of our sample). The structures associated with different velocity components present very different shapes and orientations, which sometimes need to be combined to reproduce the shape of the dark cloud. For all clouds the velocity field exhibits significant structure, as illustrated for one component of the $\mathrm{DF}+31.03+0.27$ cloud by the channel maps of Fig. 5. In this object, the profiles are complex and the gas structures seem to be connected over a wide velocity range. 

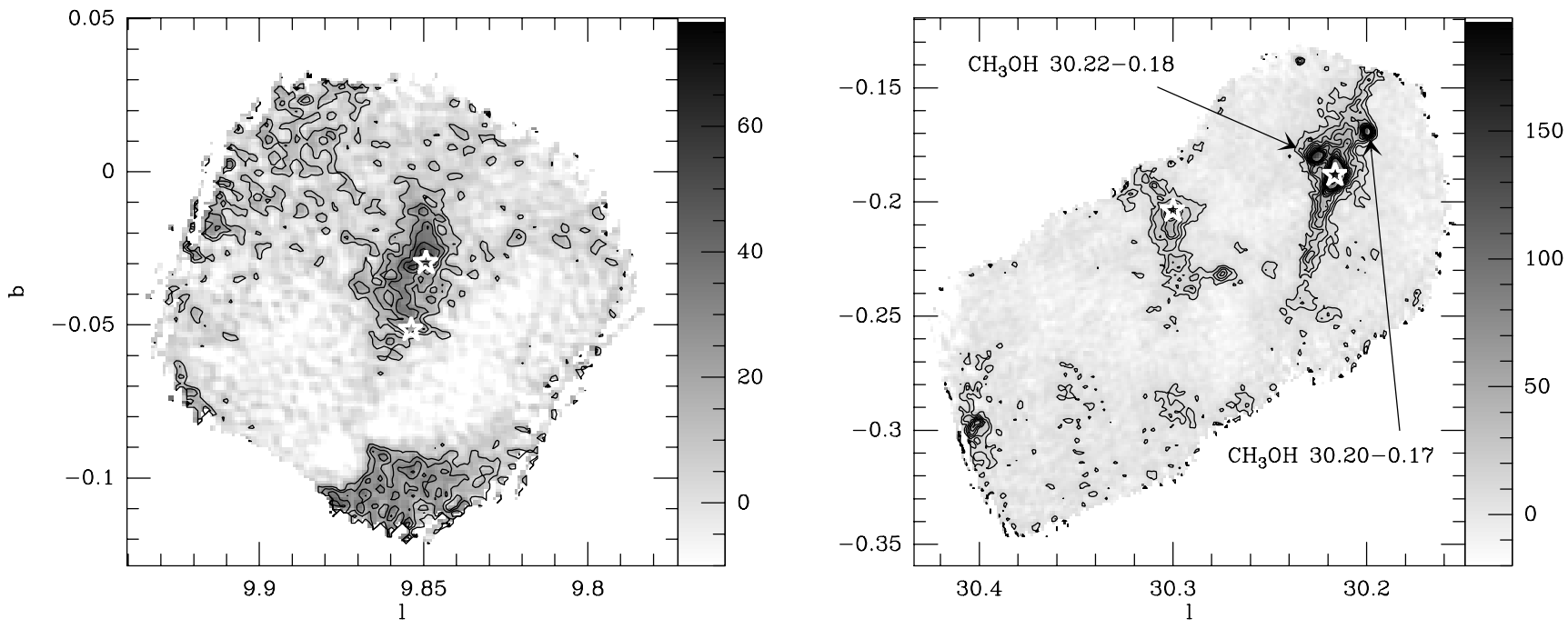

Fig. 3. Continuum maps at $1.2 \mathrm{~mm}$. Left: DF+09.86-0.04. Contours are 10 to $60 \mathrm{mJy} / 11^{\prime \prime}$ beam by steps of 10 . Right: $\mathrm{DF}+30.23-0.20$ and surroundings. Contours are 10 to $100 \mathrm{mJy} / 11^{\prime \prime}$ beam by steps of 10 , then 100 to 200 by steps of 50 . $\mathrm{CH}_{3} \mathrm{OH}$ masers detected in previous surveys (Caswell et al. 1995) are indicated. White star symbols indicate embedded stars identified in the mid-IR plates. Positions are in galactic coordinates.
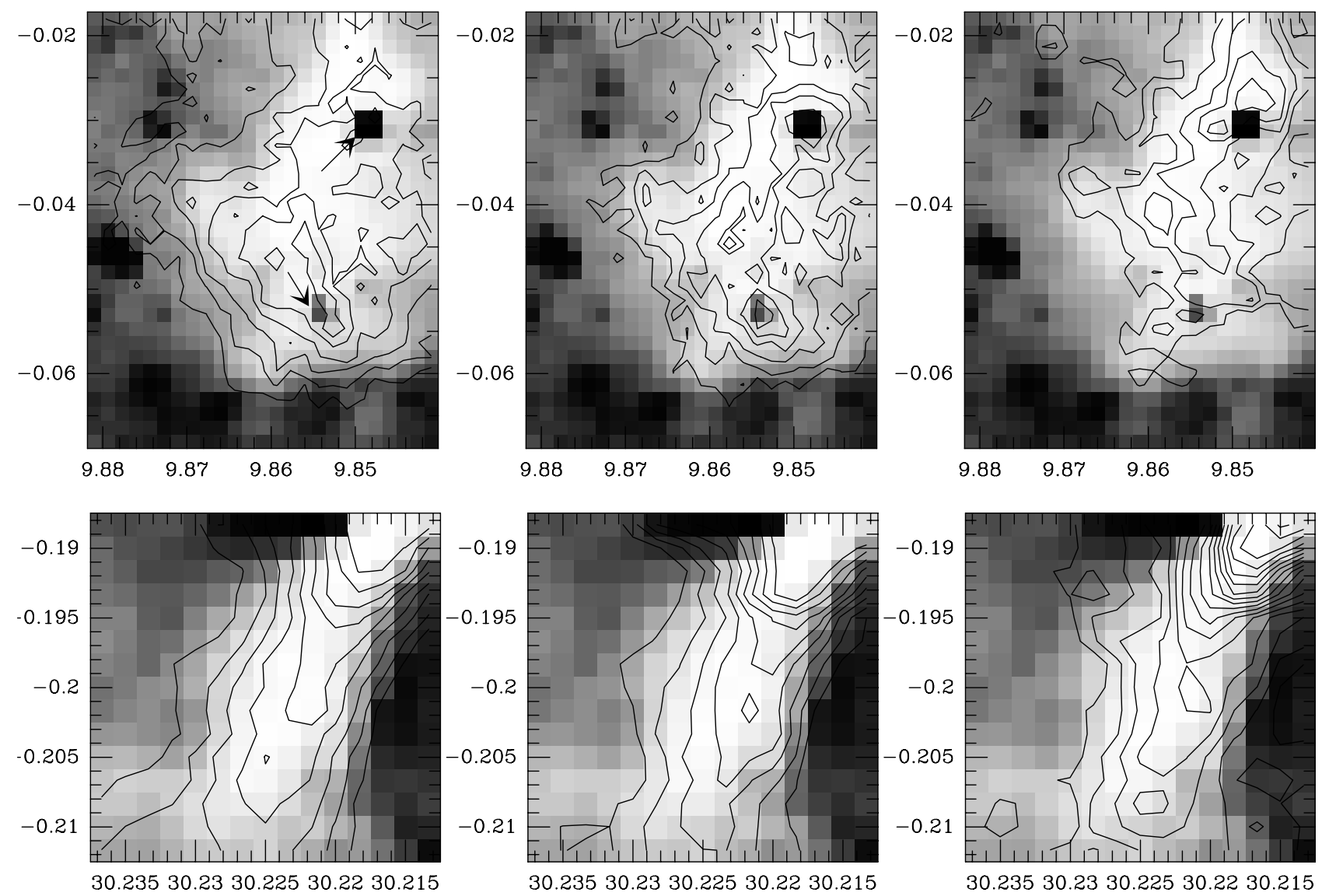

Fig. 4. Upper panels: left: contour map of the $\mathrm{C}^{18} \mathrm{O}(J=1-0)$ transition integrated emission for DF+09.86-0.04 superimposed over the corresponding ISOGAL field in the LW3 $(15 \mu \mathrm{m})$ filter. ISOGAL data have been reversed so that absorption features appear with positive values (see text). Arrows indicate positions of embedded stars. Middle: same for the $\mathrm{C}^{18} \mathrm{O}(J=2-1)$ transition. In both cases, contours are $1 \mathrm{~K} \mathrm{~km} \mathrm{~s}^{-1}$ to $4 \mathrm{~K} \mathrm{~km} \mathrm{~s}^{-1}$ by steps of 0.5 ( $T_{\mathrm{A}}^{*}$ scale), velocity interval is 16 to $20 \mathrm{~km} \mathrm{~s}^{-1}$. Right: contour map of $1.2 \mathrm{~mm}$ continuum emission for DF+09.86-0.04 superimposed over the corresponding ISOGAL field in the $L W 3$ filter. Contours are 10 to $60 \mathrm{mJy} / 11^{\prime \prime}$ beam by steps of 10 . Lower panels: same as upper panels, for DF+30.23-0.20. Contours are 4 to $12 \mathrm{~K} \mathrm{~km} \mathrm{~s}^{-1}$ by steps of 1 for both $\mathrm{C}^{18} \mathrm{O}$ maps, and 10 to $170 \mathrm{mJy} / 11^{\prime \prime}$ beam by steps of 10 for the continuum map. Coordinates are galactic longitude and latitude. 


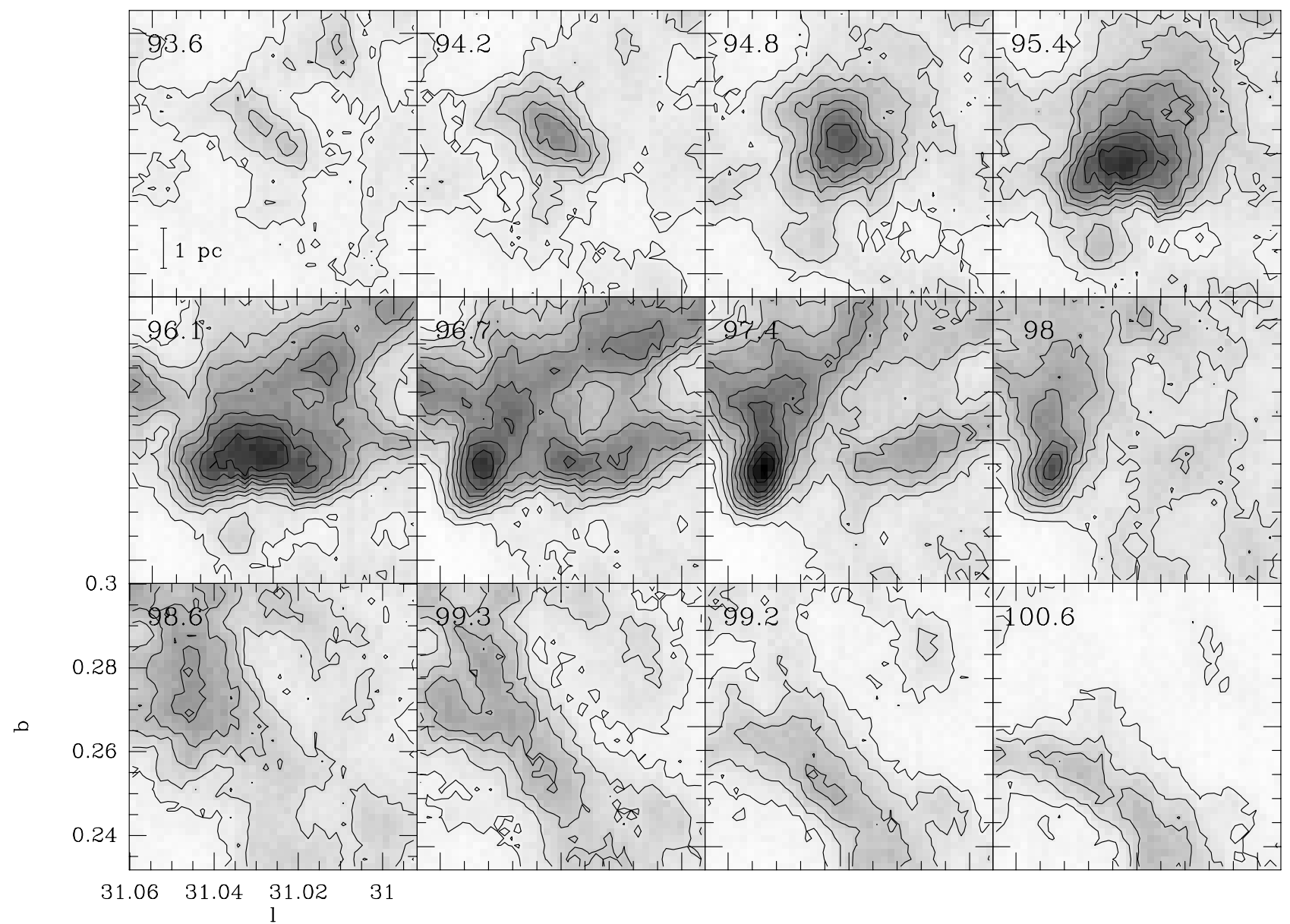

Fig. 5. ${ }^{13} \mathrm{CO}(J=1-0)$ channel maps of $\mathrm{DF}+31.03+0.27$ averaged over 3 channels of $0.21 \mathrm{~km} \mathrm{~s}^{-1}$. The central velocity in $\mathrm{km} \mathrm{s}^{-1}$ is indicated on the upper left corner for each map. Contours are 0.4 to $6.7 \mathrm{~K} \mathrm{~km} \mathrm{~s}^{-1}$ by steps of 0.7 ( $T_{\mathrm{A}}^{*}$ scale).

Large field maps obtained with the 4-m Nanten telescope in ${ }^{13} \mathrm{CO}(J=1-0)$ (Zagury et al., yet unpublished data) and shown in Fig. 6 for DF+09.86-0.04 and $\mathrm{DF}+30.23-0.20$ indicate that the IR dark clouds are not isolated objects: they are embedded in quiescent GMC's, most of them belonging to the cold GMC population detected earlier in $\mathrm{CO}$ galactic surveys (e.g. Sanders et al. 1986). This contradicts Egan et al.'s (1998) claim that the IRDCs are isolated objects.

Using the galactic rotation model of Burton et al. (1991), we are able to derive kinematic distances of these objects from the Doppler shift of the line. Assuming that the kinematic distance ambiguity is solved by the absorption bias in favour of the nearest position, we derive distances between 2.8 and $7.4 \mathrm{kpc}$ (see Table 2). For all observed clouds the inferred kinematic distances are consistent with objects lying within or in front of the molecular ring.

\subsection{Line intensities and velocity structure}

Figures 7 and 8 give examples of the line profiles observed in three of the clouds for so-called core $\left(\mathrm{C}^{18} \mathrm{O}\right.$ emission peaks) and envelope (core periphery) areas.
The lines, although often centrally peaked, rarely exhibit symmetric Gaussian profiles. In the 2 cases where embedded stars are associated with the clouds, the profiles appear as self-reversed in ${ }^{13} \mathrm{CO}(J=2-1)$ and flat-topped in ${ }^{13} \mathrm{CO}(J=1-0)$. $\mathrm{DF}+30.23-0.20$ illustrates one of these cases (upper panel of the second column of Fig. 7). The line broadening due to a higher opacity in the star vicinity is quite significant.

The absolute line intensities are smaller than what would be expected from such massive dense clouds if extrapolated from values observed in local dark clouds (Table 3). This effect is even stronger for weaker lines like $\mathrm{HC}_{3} \mathrm{~N}$ or $\mathrm{CH}_{3} \mathrm{CCH}$ where the lines are a factor of 5 weaker than in e.g. TMC-1 (Pratap et al. 1997). Part of this weakness may be attributed to a very low kinetic temperature or a small filling factor. But chemical effects or, most likely, depletion onto grains should be also considered. On the other hand, the lines are broader than in local dark clouds: this is not surprising given the large size and mass of the objects.

Line intensities ratios are compared in the scatter plots of Figs. 9 and 10. The ${ }^{13} \mathrm{CO}(J=1-0)$ to ${ }^{13} \mathrm{CO}(J=2-1)$ (noted $\left.R_{13}\right)$ and $\mathrm{C}^{18} \mathrm{O}(J=1-0)$ to $\mathrm{C}^{18} \mathrm{O}(J=2-1)$ (noted $R_{18}$ ) ratios are found to be constant on average for a given source, independent of the choice of pixels in 
Table 3. CO line parameters for spectra averaged over $30^{\prime \prime} \times 30^{\prime \prime}$ areas.

\begin{tabular}{|c|c|c|c|c|c|c|c|c|c|}
\hline \multirow[b]{2}{*}{ Name } & \multirow[b]{2}{*}{$v_{0}{ }^{(A)}$} & \multicolumn{2}{|c|}{$\overline{\mathrm{C}^{18} \mathrm{O}^{(B)}}$} & \multicolumn{2}{|c|}{$\overline{{ }^{13} \mathrm{CO}^{(B)}}$} & \multicolumn{4}{|c|}{ 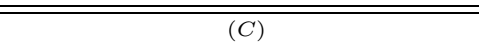 } \\
\hline & & $(J=1 \rightarrow 0)$ & $(J=2 \rightarrow 1)$ & $(J=1 \rightarrow 0)$ & $(J=2 \rightarrow 1)$ & $R_{18}$ & $R_{13}$ & $R_{10}$ & $R_{21}$ \\
\hline $\begin{array}{l}\text { DF+04.36-0.06 } \\
\text { core }\end{array}$ & 11.42 & $\begin{array}{c}3.34(0.08) \\
1.71\end{array}$ & $\begin{array}{c}2.26(0.17) \\
1.78\end{array}$ & - & $\begin{array}{c}5.00(0.14) \\
1.80\end{array}$ & $\begin{array}{c}0.677 \\
(0.065)\end{array}$ & - & - & $\begin{array}{c}2.21 \\
(0.23)\end{array}$ \\
\hline envelope & 11.37 & $\begin{array}{c}2.10(0.08) \\
1.61\end{array}$ & $\begin{array}{c}1.54(0.17) \\
1.76\end{array}$ & - & $\begin{array}{c}4.05(0.14) \\
2.70\end{array}$ & $\begin{array}{c}0.731 \\
(0.106)\end{array}$ & - & - & $\begin{array}{c}2.64 \\
(0.38)\end{array}$ \\
\hline $\begin{array}{l}\mathrm{DF}+09.86-0.04 \\
\text { core }^{(E)}\end{array}$ & 17.79 & $\begin{array}{c}1.97(0.05) \\
2.01\end{array}$ & $\begin{array}{c}2.29(0.10) \\
1.81\end{array}$ & $\begin{array}{c}6.90(0.05) \\
2.52\end{array}$ & $\begin{array}{c}6.22(0.10) \\
2.80\end{array}$ & $\begin{array}{c}1.160 \\
(0.081)\end{array}$ & $\begin{array}{c}0.900 \\
(0.020)\end{array}$ & $\begin{array}{c}3.50 \\
(0.11)\end{array}$ & $\begin{array}{c}2.72 \\
(0.16)\end{array}$ \\
\hline envelope & 17.69 & $\begin{array}{c}1.30(0.05) \\
2.12\end{array}$ & $\begin{array}{c}1.39(0.10) \\
1.63\end{array}$ & $\begin{array}{c}4.94(0.05) \\
2.26\end{array}$ & $\begin{array}{c}4.87(0.10) \\
2.23\end{array}$ & $\begin{array}{l}1.065 \\
(0.118)\end{array}$ & $\begin{array}{c}0.986 \\
(0.029)\end{array}$ & $\begin{array}{c}3.78 \\
(0.19)\end{array}$ & $\begin{array}{c}3.50 \\
(0.32)\end{array}$ \\
\hline $\begin{array}{l}\mathrm{DF}+15.05+0.09 \\
\text { core }^{(E)}\end{array}$ & 29.95 & $\begin{array}{c}2.84(0.08) \\
2.05\end{array}$ & $\begin{array}{c}2.16(0.13) \\
2.13\end{array}$ & $\begin{array}{c}5.80(0.08) \\
2.56\end{array}$ & $\begin{array}{c}4.16(0.11) \\
1.70\end{array}$ & $\begin{array}{c}0.763 \\
(0.066)\end{array}$ & $\begin{array}{c}0.717 \\
(0.029)\end{array}$ & $\begin{array}{c}2.04 \\
(0.09)\end{array}$ & $\begin{array}{c}1.92 \\
(0.17)\end{array}$ \\
\hline envelope & 29.97 & $\begin{array}{c}2.02(0.08) \\
2.13\end{array}$ & $\begin{array}{c}1.34(0.13) \\
2.20\end{array}$ & - & $\begin{array}{c}3.27(0.11) \\
1.80\end{array}$ & $\begin{array}{c}0.664 \\
(0.091)\end{array}$ & - & - & $\begin{array}{c}2.44 \\
(0.32)\end{array}$ \\
\hline \multicolumn{10}{|l|}{$\mathrm{DF}+18.56-0.15$} \\
\hline & & 1.90 & 1.40 & 3.25 & 3.31 & $(0.070)$ & $(0.032)$ & $(0.09)$ & $(0.36)$ \\
\hline envelope & 50.60 & $\begin{array}{c}1.88(0.09) \\
1.53\end{array}$ & $\begin{array}{c}1.16(0.17) \\
1.27\end{array}$ & $\begin{array}{c}5.33(0.09) \\
2.96\end{array}$ & $\begin{array}{c}3.32(0.16) \\
2.84\end{array}$ & $\begin{array}{c}0.621 \\
(0.120)\end{array}$ & $\begin{array}{c}0.622 \\
(0.041)\end{array}$ & $\begin{array}{c}2.85 \\
(0.19)\end{array}$ & $\begin{array}{l}2.85 \\
(0.55)\end{array}$ \\
\hline $\begin{array}{l}\mathrm{DF}+30.23-0.20 \\
\text { star vicinity }\end{array}$ & 104.7 & $\begin{array}{c}5.53(0.05) \\
2.52\end{array}$ & $\begin{array}{c}7.62(0.13) \\
2.77\end{array}$ & $\begin{array}{c}14.40(0.05) \\
3.88\end{array}$ & $\begin{array}{c}13.09^{(D)}(0.13) \\
4.82\end{array}$ & $\begin{array}{c}1.378 \\
(0.037)\end{array}$ & $\begin{array}{c}0.912 \\
(0.012)\end{array}$ & $\begin{array}{c}2.60 \\
(0.03)\end{array}$ & $\begin{array}{c}1.72 \\
(0.05)\end{array}$ \\
\hline filament & 104.7 & $\begin{array}{c}4.23(0.05) \\
2.23\end{array}$ & $\begin{array}{c}5.30(0.13) \\
2.28\end{array}$ & $\begin{array}{c}11.90(0.05) \\
3.22\end{array}$ & $\begin{array}{c}10.87(0.13) \\
3.60\end{array}$ & $\begin{array}{l}1.252 \\
(0.047)\end{array}$ & $\begin{array}{c}0.914 \\
(0.014)\end{array}$ & $\begin{array}{c}2.81 \\
(0.05)\end{array}$ & $\begin{array}{l}2.05 \\
(0.08)\end{array}$ \\
\hline $\begin{array}{l}\mathrm{DF}+30.36+0.11 \\
\text { core }^{(E)} \\
\text { (1st component) }\end{array}$ & 96.1 & $\begin{array}{c}2.40(0.09) \\
3.64\end{array}$ & $\begin{array}{c}3.23(0.17) \\
3.07\end{array}$ & $\begin{array}{c}8.32(0.09) \\
3.42\end{array}$ & $\begin{array}{c}7.53(0.17) \\
3.01\end{array}$ & $\begin{array}{c}1.349 \\
(0.122)\end{array}$ & $\begin{array}{c}0.905 \\
(0.030)\end{array}$ & $\begin{array}{c}3.47 \\
(0.17)\end{array}$ & $\begin{array}{c}2.33 \\
(0.18)\end{array}$ \\
\hline envelope & 96.0 & $\begin{array}{c}2.29(0.09) \\
3.14\end{array}$ & $\begin{array}{c}2.28(0.17) \\
2.724\end{array}$ & - & $\begin{array}{c}7.23(0.17) \\
4.09\end{array}$ & $\begin{array}{c}0.997 \\
(0.114)\end{array}$ & - & - & $\begin{array}{c}3.17 \\
(0.31)\end{array}$ \\
\hline $\begin{array}{l}\operatorname{core}^{(E)} \\
\text { (2nd component) }\end{array}$ & 111.0 & $\begin{array}{c}4.00(0.09) \\
1.27\end{array}$ & $\begin{array}{c}4.77(0.20) \\
1.31\end{array}$ & - & $\begin{array}{c}9.47(0.18) \\
1.72\end{array}$ & $\begin{array}{l}1.191 \\
(0.076)\end{array}$ & - & - & $\begin{array}{l}1.99 \\
(0.12)\end{array}$ \\
\hline envelope & 111.3 & $\begin{array}{c}1.40(0.09) \\
1.57\end{array}$ & $\begin{array}{c}1.94(0.20) \\
1.77\end{array}$ & $\begin{array}{l}5.65(0.09) \\
2.22\end{array}$ & $\begin{array}{l}4.52(0.18) \\
2.22\end{array}$ & $\begin{array}{l}1.383 \\
(0.230)\end{array}$ & $\begin{array}{c}0.800 \\
(0.045)\end{array}$ & $\begin{array}{c}4.04 \\
(0.32)\end{array}$ & $\begin{array}{l}2.33 \\
(0.33)\end{array}$ \\
\hline $\begin{array}{l}\mathrm{DF}+31.03+0.27 \\
\text { core }\end{array}$ & 77.8 & $2.12(0.05)$ & $1.56(0.13)$ & $4.76(0.05)$ & $2.85(0.13)$ & 0.736 & 0.597 & 2.25 & 1.82 \\
\hline (1st component) & & 2.81 & & 3.78 & 2.98 & $(0.078)$ & $(0.033)$ & $(0.08)$ & $(0.23)$ \\
\hline envelope & 78.2 & $\begin{array}{c}1.36(0.05) \\
3.17\end{array}$ & $\begin{array}{c}0.86(0.13) \\
2.86\end{array}$ & $\begin{array}{c}3.65(0.05) \\
3.81\end{array}$ & $\begin{array}{c}2.35(0.13) \\
3.82\end{array}$ & $\begin{array}{c}0.633 \\
(0.118)\end{array}$ & $\begin{array}{l}0.645 \\
(0.044)\end{array}$ & $\begin{array}{c}2.69 \\
(0.14)\end{array}$ & $\begin{array}{l}2.73 \\
(0.55)\end{array}$ \\
\hline $\begin{array}{l}\text { core } \\
\text { (2nd component) }\end{array}$ & 96.0 & $\begin{array}{l}2.78(0.05) \\
2.05\end{array}$ & $\begin{array}{c}2.96(0.17) \\
1.82\end{array}$ & $\begin{array}{c}8.25(0.05) \\
3.42\end{array}$ & $\begin{array}{c}5.38(0.15) \\
3.10\end{array}$ & $\begin{array}{l}1.063 \\
(0.080)\end{array}$ & $\begin{array}{c}0.653 \\
(0.022)\end{array}$ & $\begin{array}{c}2.96 \\
(0.07)\end{array}$ & $\begin{array}{r}1.82 \\
(0.15)\end{array}$ \\
\hline envelope & 96.2 & $\begin{array}{c}1.51(0.05) \\
3.71\end{array}$ & $\begin{array}{c}1.56(0.17) \\
2.49\end{array}$ & $\begin{array}{c}5.73(0.05) \\
4.00\end{array}$ & $\begin{array}{c}4.18(0.15) \\
3.69\end{array}$ & $\begin{array}{l}1.033 \\
(0.146)\end{array}$ & $\begin{array}{c}0.729 \\
(0.033)\end{array}$ & $\begin{array}{c}3.78 \\
(0.16)\end{array}$ & $\begin{array}{c}2.67 \\
(0.38)\end{array}$ \\
\hline $\begin{array}{l}\mathrm{DF}+51.47+0.00 \\
\text { core }\end{array}$ & 5 & & & & & & & & \\
\hline & 34.14 & $\begin{array}{l}2.04(0.04) \\
1.81\end{array}$ & 1.80 & 3.40 & 2.91 & $(0.063)$ & $(0.030)$ & $(0.04)$ & $(0.16)$ \\
\hline envelope & 54.38 & $\begin{array}{c}1.73(0.04) \\
2.12\end{array}$ & $\begin{array}{c}1.64(0.13) \\
2.06\end{array}$ & $\begin{array}{c}4.51(0.04) \\
3.31\end{array}$ & $\begin{array}{l}3.22(0.12) \\
2.82\end{array}$ & $\begin{array}{c}0.948 \\
(0.097)\end{array}$ & $\begin{array}{c}0.714 \\
(0.032)\end{array}$ & $\begin{array}{c}2.61 \\
(0.08)\end{array}$ & $\begin{array}{l}1.96 \\
(0.23)\end{array}$ \\
\hline
\end{tabular}

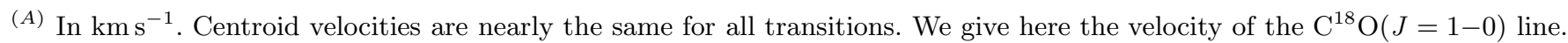

${ }^{(B)}$ In each case, we give the peak temperature $\left(\mathrm{K}\right.$, in $T_{\mathrm{mb}}^{\prime}$ scale, see Appendix A.1) with its noise rms $\left(1 \sigma_{\mathrm{rms}}\right)$ in brackets and the line width $\left(\mathrm{km} \mathrm{s}^{-1}, F W H M=2.35 \sigma\right)$. Temperatures correspond to data smoothed to the same spatial $\left(22^{\prime \prime}\right)$ and velocity $\left(0.213 \mathrm{~km} \mathrm{~s}^{-1}\right)$ resolution.

(C) Brackets give the uncertainty on ratios based only on the spectra rms noise.

(D) Extrapolated from self-reversed spectra.

(E) Overlap with star clusters identified on the ISOGAL plates. 

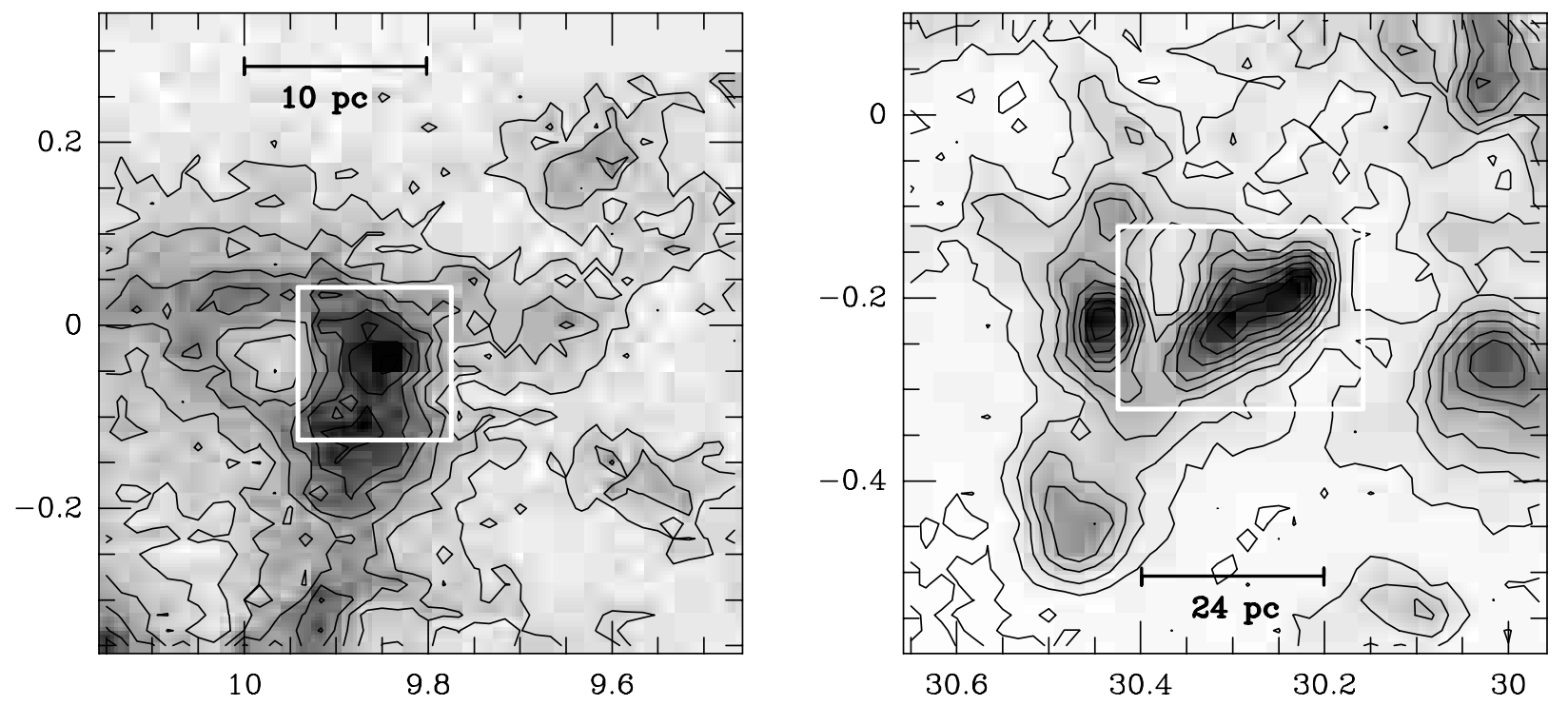

Fig. 6. Large field maps of $\mathrm{DF}+09.86-0.04$ (left) and $\mathrm{DF}+30.23-0.20$ (right) in the ${ }^{13} \mathrm{CO}(J=1-0)$ transition. Beam $\mathrm{HPBW}$ is $2.5^{\prime}$ and sampling interval is $1^{\prime}$. Velocities are integrated between 16 and $20 \mathrm{~km} \mathrm{~s}^{-1}$ and 104 and $107 \mathrm{~km} \mathrm{~s}{ }^{-1}$ respectively. The spatial connections with larger scale structures is clear. White boxes indicate the extent of the bolometer maps displayed in Fig. 3.

the line centre or wings, in the cloud core or envelope. A similar result was found by e.g. Falgarone et al. (1998) for dense cores close to the Sun $(d \lesssim 150 \mathrm{pc})$. A significant departure from this general behaviour is however observed in the close vicinity of the young stellar objects of $\mathrm{DF}+30.23-0.20$ : in the line wings the $R_{13}$ ratio is higher than the average value obtained for the filament (rightmost data points of Fig. 10). The excitation is certainly higher and the $(J=2-1)$ transition is optically thicker than the $(J=1-0)$ one, which results in a broader line and eventually in some self-absorption (Fig. 7).

Table 4 compiles the best-fit results of these ratios. The ratios between integrated intensities are also given for comparison with previous ${ }^{12} \mathrm{CO}$ studies. These results can be compared to values observed in other clouds of our Galaxy: in quiescent clouds of the solar neighbourhood, Falgarone et al. (1998) found a mean of $0.65 \pm 0.15$ for ${ }^{12} \mathrm{CO}$ and ${ }^{13} \mathrm{CO}$. The $\mathrm{C}^{18} \mathrm{O}$ observations reported by Kramer et al. (1999) in IC5146 lead to a mean value of $0.83 \pm 0.22$. Several studies have been conducted in the Galactic plane in ${ }^{12} \mathrm{CO}$, showing a large-scale gradient of the integrated intensity ratios: 0.75 at $\sim 4 \mathrm{kpc}$ from the Galactic centre, to 0.5 at $8 \mathrm{kpc}$ from the Galactic centre (e.g. Sakamoto et al. 1995, who derive a mean value of $0.66 \pm 0.01)$. A similar study conducted by Oka et al. (1998) in the Taurus and the Orion A Molecular Clouds, including star-forming sites, lead to mean values of $0.53 \pm 0.01$ and $0.75 \pm 0.01$ respectively.

Our mean values of $0.72 \pm 0.16\left({ }^{13} \mathrm{CO}\right)$ and $0.90 \pm$ $0.29\left(\mathrm{C}^{18} \mathrm{O}\right)$ are higher than the values found in these published studies. Even the starless sub-sample shows rather high values: $0.67 \pm 0.12\left({ }^{13} \mathrm{CO}\right)$ and $0.79 \pm 0.22\left(\mathrm{C}^{18} \mathrm{O}\right)$. Provided relative calibration uncertainties can be
Table 4. $J=2-1$ to $J=1-0$ ratios for $\mathrm{C}^{18} \mathrm{O}$ and ${ }^{13} \mathrm{CO}$ estimated over the entire clouds.

\begin{tabular}{lcccc}
\hline \hline Name & $R_{18}$ & $R_{18}^{I(A)}$ & $R_{13}$ & $R_{13}^{I(A)}$ \\
\hline $\mathrm{DF}+04.36-0.06$ & 0.66 & 0.84 & 0.59 & 0.60 \\
$\mathrm{DF}+09.86-0.04$ & 0.96 & 1.26 & 0.93 & 0.92 \\
$\mathrm{DF}+15.05+0.09$ & 0.62 & 0.82 & 0.72 & 0.78 \\
$\mathrm{DF}+18.56-0.15$ & $-{ }^{(B)}$ & $-^{(B)}$ & 0.59 & 0.61 \\
$\mathrm{DF}+18.79-0.03$ & 1.02 & 1.18 & 0.66 & 0.70 \\
$\mathrm{DF}+25.90-0.17$ & $-{ }^{(B)}$ & 0.70 & 0.53 & 0.60 \\
$\mathrm{DF}+30.23-0.20^{(C)}$ & 1.58 & 1.63 & 1.02 & 1.01 \\
$\mathrm{DF}+30.36+0.11$ & 1.07 & 1.17 & 0.74 & 0.87 \\
" (2nd component) & 0.90 & 1.24 & 0.94 & 0.79 \\
DF+31.03+0.27 & 0.63 & 0.85 & 0.61 & 0.69 \\
"(2nd component) & 0.84 & 1.07 & 0.75 & 0.82 \\
$\mathrm{DF}+51.47+0.00$ & 0.70 & 0.78 & 0.60 & 0.63 \\
\hline Mean & 0.90 & 1.05 & 0.72 & 0.75 \\
$(1-\sigma$ deviations $)$ & \pm 0.28 & \pm 0.27 & \pm 0.15 & \pm 0.13 \\
\hline
\end{tabular}

(A) Ratio of integrated intensities.

(B) Dispersion is too large.

(C) Measured between 103 and $110 \mathrm{~km} \mathrm{~s}^{-1}$.

excluded, these values may be characteristic of the advanced condensation stage of IRDC's.

The comparison of ${ }^{13} \mathrm{CO}$ and $\mathrm{C}^{18} \mathrm{O}$ line intensities (called $R_{10}$ and $R_{21}$ in Table 1 for $J=1-0$ and $J=2-1$ respectively) illustrate the differential abundances, excitation states and optical depths of the two CO isotopomers. At low intensities (yet above $5 \sigma$ ), these intensity ratios are consistent with the local interstellar $\left[{ }^{13} \mathrm{CO}\right] /\left[\mathrm{C}^{18} \mathrm{O}\right]$ ratio of about 7.3 (deduced from $\left[{ }^{16} \mathrm{O}\right] /\left[{ }^{18} \mathrm{O}\right]=560$ and 

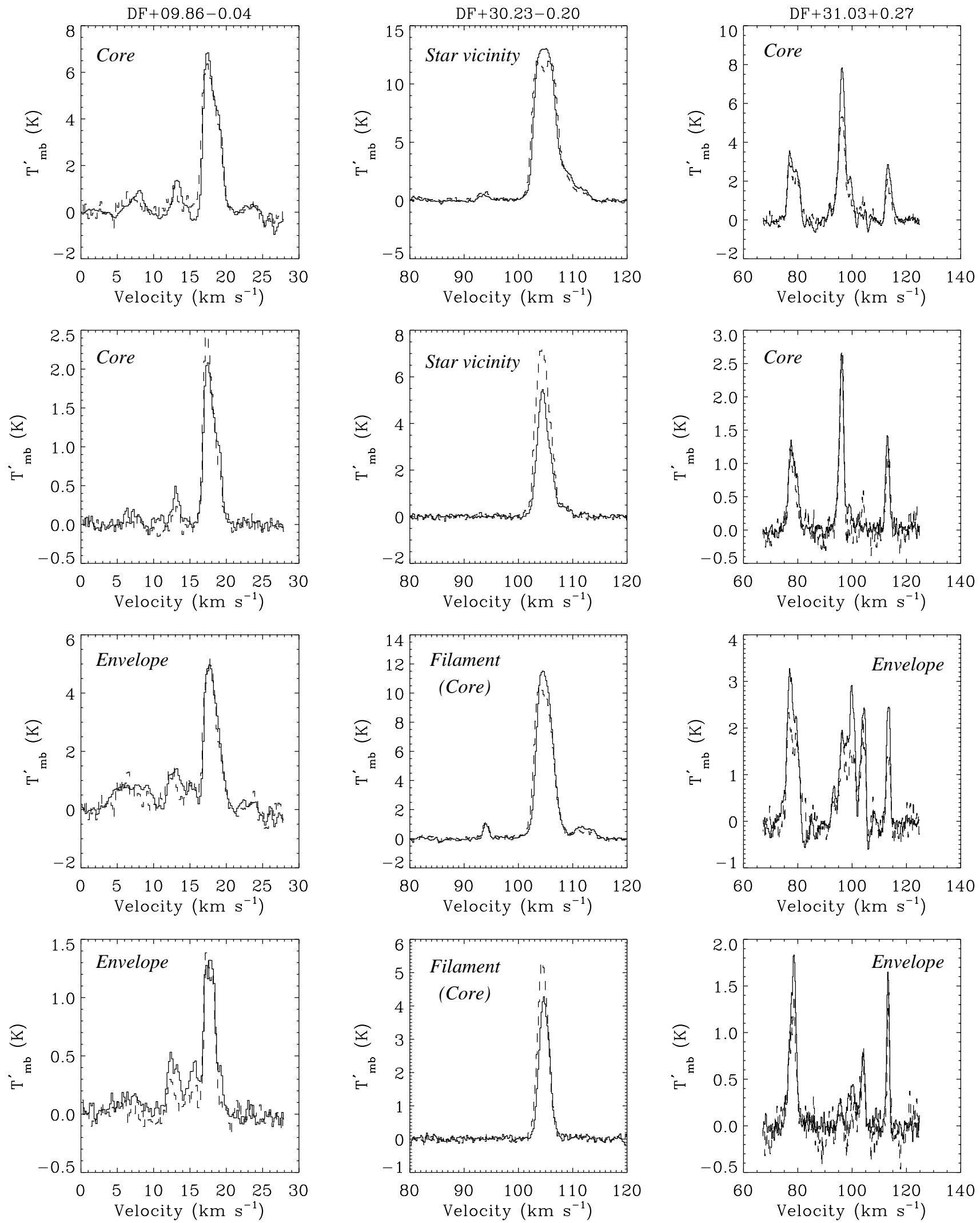

Fig. 7. Average spectra of $\mathrm{CO}$ isotopomers for $\mathrm{DF}+09.86-0.04, \mathrm{DF}+30.23-0.20$ and $\mathrm{DF}+31.03+0.27$. First row of panels: ${ }^{13} \mathrm{CO}(J=1-0)$ (full lines) and ${ }^{13} \mathrm{CO}(J=2-1)$ (dashed lines) transitions in the core area. Second row of panels: $\mathrm{C}^{18} \mathrm{O}(J=1-0)$ (full lines) and $\mathrm{C}^{18} \mathrm{O}(J=2-1)$ (dashed lines) in the core (or star vicinity) area. Third and fourth rows of panels: same as 1 st and 2 nd rows for a different area of the same clouds. The spectra have been convolved to identical resolution $\left(22^{\prime \prime}\right.$ and $0.213 \mathrm{~km} \mathrm{~s}{ }^{-1}$ channels), and averaged over $30^{\prime \prime}$ boxes. Temperatures are in the $T_{\mathrm{mb}}^{\prime}$ scale (see Appendix A.1). 

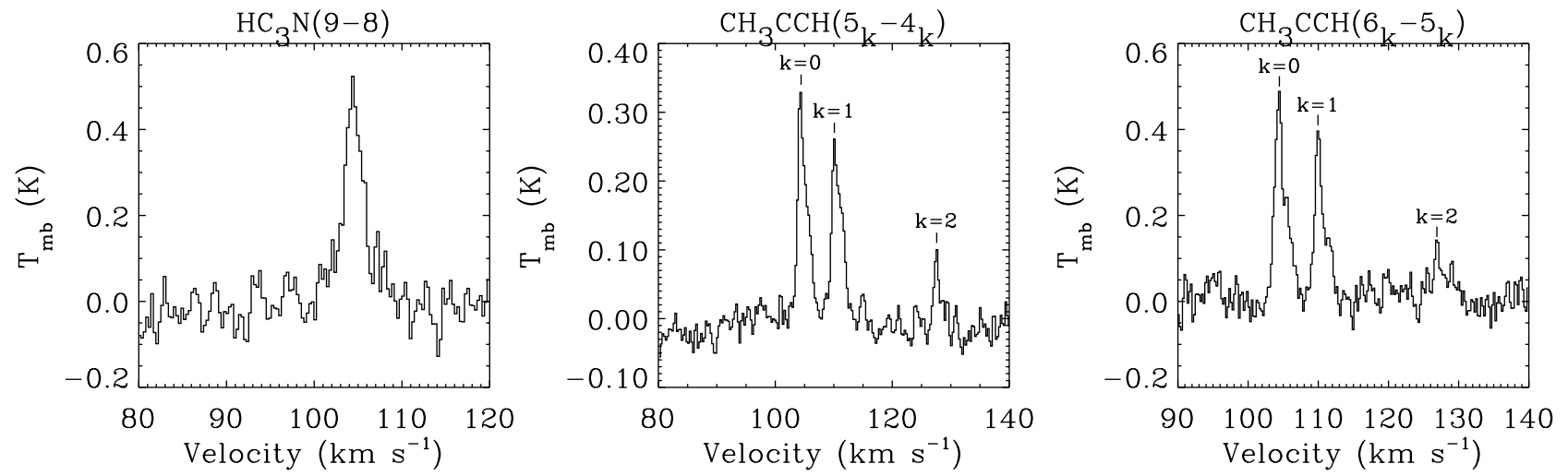

Fig. 8. Sample spectra of $\mathrm{HC}_{3} \mathrm{~N}, \mathrm{CH}_{3} \mathrm{CCH}(J=5-4)$ and $\mathrm{CH}_{3} \mathrm{CCH}(J=6-5)$ for $\mathrm{DF}+30.23-0.20$ in the star vicinity.
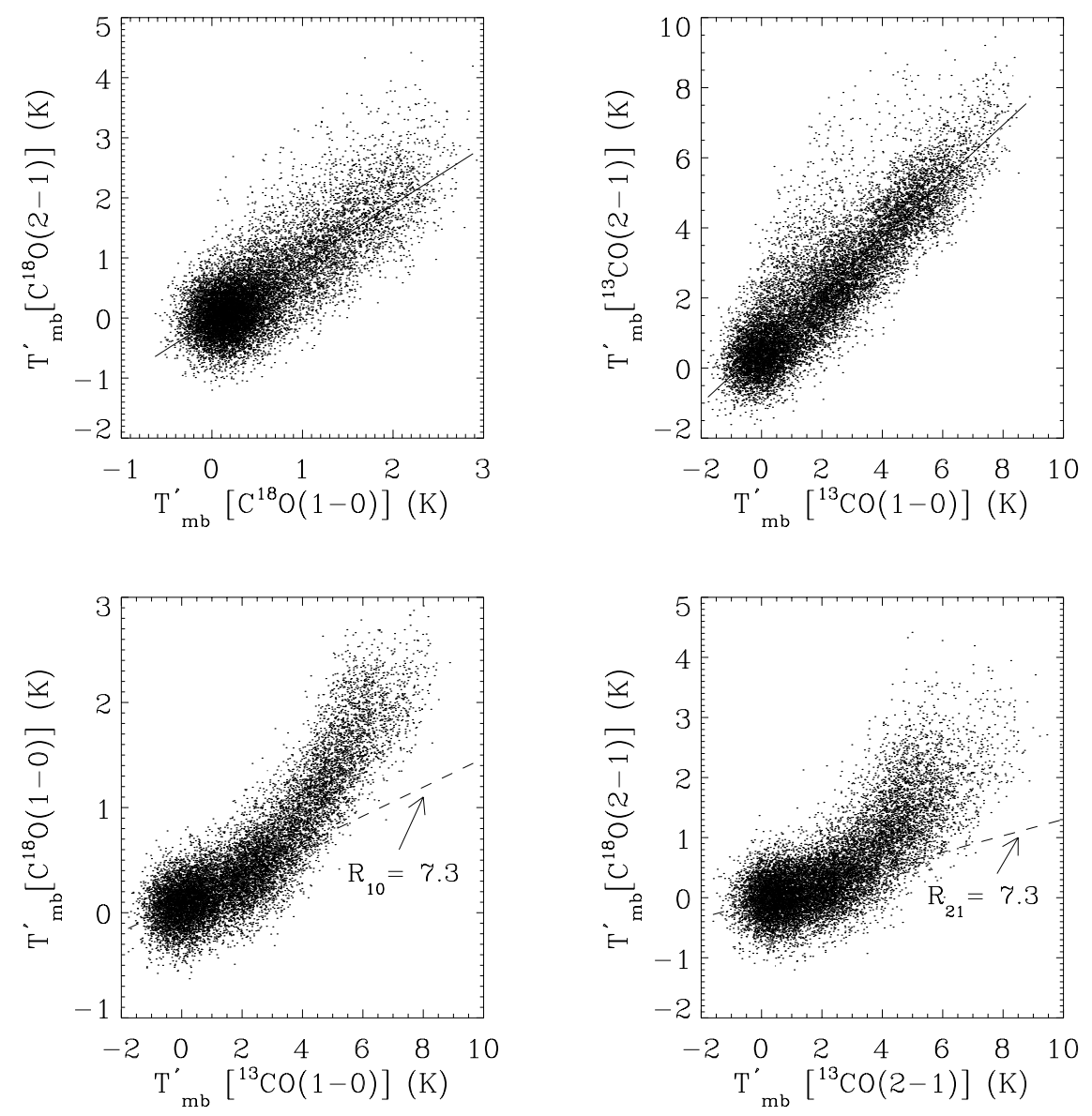

Fig. 9. Scatter plots of CO isotopomer pairs of temperatures $T_{\mathrm{mb}}^{\prime}$ for $\mathrm{DF}+09.86-0.04$ (see text). The data have been smoothed to a $22^{\prime \prime}$ spatial and $0.2 \mathrm{~km} \mathrm{~s}^{-1}$ spectral resolution. Velocities considered are between 16 and $20 \mathrm{~km} \mathrm{~s}^{-1}$. Each $3-\mathrm{d}$ pixel is represented by a dot. Best-fit results are plotted for the upper panels. Local ISM ratios are indicated by dashed-lines in the bottom diagrams.

$\left[{ }^{12} \mathrm{C}\right] /\left[{ }^{13} \mathrm{C}\right]=77$, Wilson \& Rood 1994), but they depart from this value as intensities increase. The ratios drop below 2 close to the emission peaks. These ratios are systematically larger in the envelope than in the core areas. The slow apparent saturation of the stronger line should be accounted for by detailed models.

\section{Cloud properties}

Preliminary results are derived from a simple analysis of the available data: spectroscopic intensities are interpreted with "LVG" calculations, which should be seen as the lowest order approximation (1-zone) to radiative transfer calculations. 

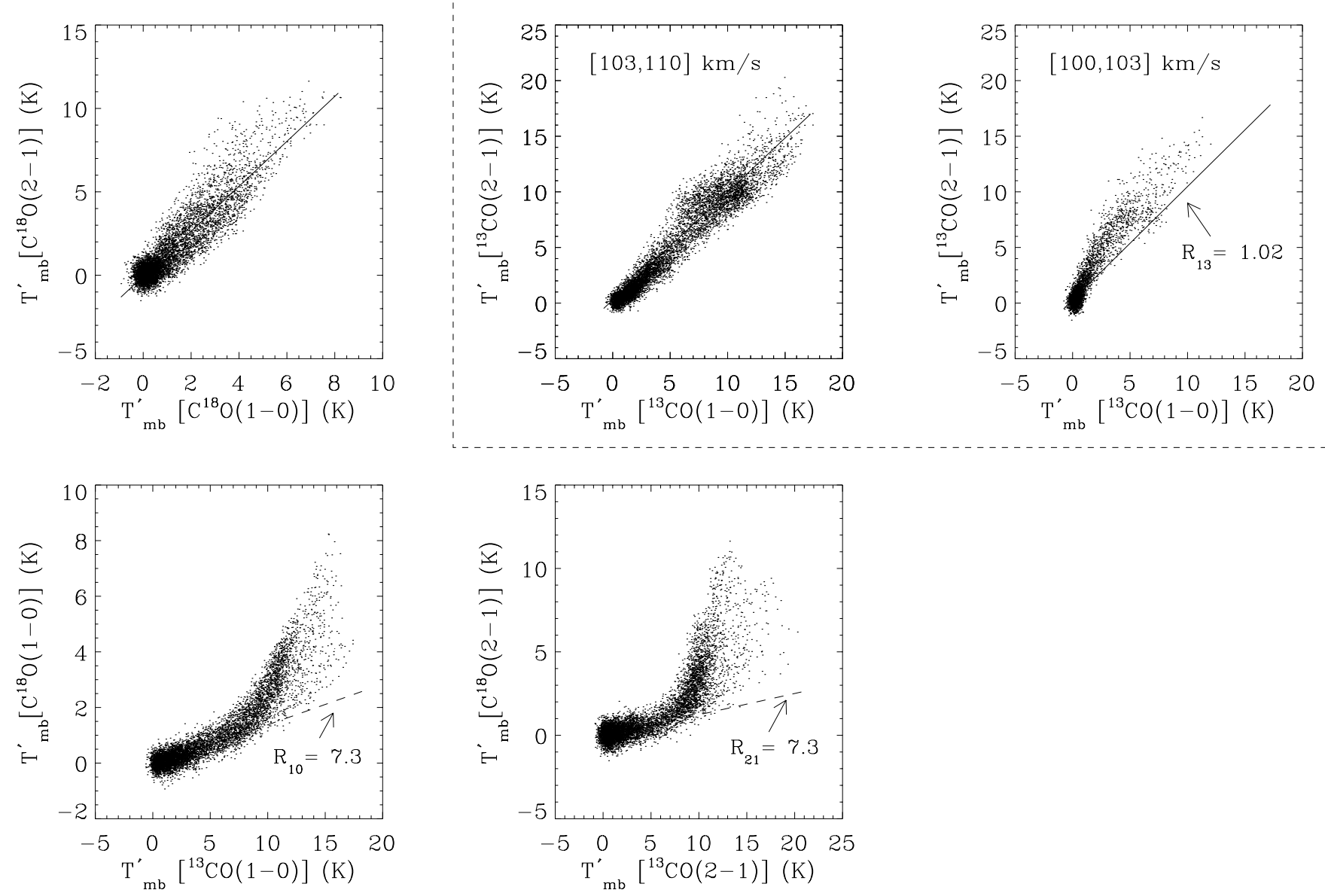

Fig. 10. Same as Fig. 9 for $\mathrm{DF}+30.23-0.20$. The velocity range is 100 to $110 \mathrm{~km} \mathrm{~s}^{-1}$, except for the ${ }^{13} \mathrm{CO}(J=1-0)$ to ${ }^{13} \mathrm{CO}(J=2-1)$ scatter plots where the correlations are given for two separate velocity ranges. The slope plotted in these latter diagrams corresponds to the best-fit results of the data considered between 103 and $110 \mathrm{~km} \mathrm{~s}^{-1}$.

\subsection{Temperatures and densities from spectroscopic data}

We used the spectra obtained in the $J=5-4$ and 6-5 transitions of $\mathrm{CH}_{3} \mathrm{CCH}$ (Fig. 8) to derive the kinetic temperatures in a subset of lines of sight. The details of this analysis will be presented in a subsequent paper (Teyssier et al. 2001b). The temperatures inferred are in the range $8-25 \mathrm{~K}$. The highest temperatures are representative of clouds with embedded stars (e.g. DF $+30.23-0.20)$. These are also the only areas where significant emission is detected in the $K=2$ rotation level.

We use these temperatures to derive densities and molecular column densities from LVG simulations of $\mathrm{HC}_{3} \mathrm{~N},{ }^{13} \mathrm{CO}$ and $\mathrm{C}^{18} \mathrm{O}$. The $\mathrm{HC}_{3} \mathrm{~N}$ transitions are relatively close in energy so that the error bars are somewhat large. The densities derived are larger than $10^{5} \mathrm{~cm}^{-3}$ in the densest parts (cores). Observations of lower frequency transitions are included for more accurate derivations in our subsequent paper (Teyssier et al. 2001b). The corresponding masses vary between $2 \times 10^{2}$ and $2 \times 10^{4} M_{\odot}$.
The temperatures and densities of our sample clouds are similar to the parameters reported by Carey et al. (1998) for the MSX IRDC's.

\subsection{Column density comparison}

For several of the sources we can compare independent estimates of total column densities: from mid-IR opacities, from dust $1 \mathrm{~mm}$ emission, from densities and size estimates, or from the column densities of tracers.

The first method consists in relating the mid-IR opacities to visible extinctions, hence total gas column density. The dust emissivity model of Draine \& Lee (1984, hereafter DL84) implies:

$A_{\mathrm{v}} \simeq 65 \times \tau_{7 \mu \mathrm{m}}$.

The total column density along the line of sight can then is estimated using the $\left(N_{\mathrm{H}+\mathrm{H}_{2}}, A_{\mathrm{V}}\right)$ relation of Bohlin et al. (1978). 
The second method is based on continuum measurements of the optically thin dust at $1.2 \mathrm{~mm}$ and uses the relation described in Motte et al. (1998):

$N_{\mathrm{H}_{2}}=\frac{S_{1.2 \mathrm{~mm}}}{\Omega_{\text {beam }} \mu m_{\mathrm{H}} \kappa_{1.2} B_{1.2}\left(T_{\text {dust }}\right)}$

where $S_{\mathrm{mm}}$ is the $1.2 \mathrm{~mm}$ flux density in mJy per $11^{\prime \prime}$ beam, $\mu$ the mean molecular weight, $m_{\mathrm{H}}$ the mass of atomic hydrogen, $B_{1.2}(T)$ the Planck function at wavelength $1.2 \mathrm{~mm}$ and temperature $T$, and $\kappa_{1.2}$ the dust mass opacity at $1.2 \mathrm{~mm}$. We adopted a value $\kappa_{1.2}=$ $0.003 \mathrm{~cm}^{2} \mathrm{~g}^{-1}$, consistent with the DL84 dust model and the $\left(N_{\mathrm{H}+\mathrm{H}_{2}}, A_{\mathrm{V}}\right)$ relation used in method (1). Such a value is believed to be suited to pre-stellar dense clumps and cores with a typical uncertainty of a factor of $\sim 2$ (see Motte et al. 1998 and ref. therein for a complete discussion). The dust temperature is assumed to be equal to the gas temperature as estimated in Sect. 4.1.

In the third method we assume that the $\mathrm{H}_{2}$ density derived from beam-averaged spectra is representative of the density within a sphere of projected size in the sky equal to the beam diameter. This assumption seems viable, in view of the apparent size of the core regions, but might be very uncertain, if the gas distribution is lacunar. Estimates are given both from $\mathrm{HC}_{3} \mathrm{~N}$ (method (3)) and from $\mathrm{C}^{18} \mathrm{O}$ (method (3')).

Finally (method (4)), we used the $\left(N_{\mathrm{H}_{2}}, W\left(\mathrm{C}^{18} \mathrm{O}\right)\right)$ relation derived by Cernicharo \& Guélin (1987, hereafter CG87) in local dark clouds. Table 5 gathers our results.

The column densities range from a few $10^{22}$ to at most a few $10^{23} \mathrm{~cm}^{-2}$. The ratio of the estimates from methods (1) and (2) is within $\pm 15 \%$ of 0.65 for all 4 cases where both estimates are available. A higher value of the emissivity at $1.2 \mathrm{~mm}$ (1.6 times the DL84 value) is required for matching the 2 derivations. This agrees with observations of cold condensations in the solar neighbourhood (e.g. Dupac et al. 2001). A proper account of the dust temperature distribution is in all cases requested for deriving more accurate conclusions.

Estimates from method (4) are 2 to 9 times smaller than values traced by the dust, the better agreement corresponding to the embedded star cluster of DF $+30.23-0.20$. Since most of the reported points have high $A_{\mathrm{v}}$, this trend suggests possible molecular depletion onto very cold grains (see next section).

Since we considered the same core size for both cases (3) and (3'), the discrepancy between these two estimates is not surprising: it illustrates how the density derivations are limited by the different critical densities (e.g. Evans 1980). On the other hand, the column densities derived from $\mathrm{HC}_{3} \mathrm{~N}((\mathbf{3}))$ are generally higher than those inferred from the dust $(\mathbf{( 1 )},(\mathbf{2}))$. This may indicate that the actual volume filling factor is smaller than 1 , the value assumed for this estimate. As in the picture proposed by Lada et al. (1997) in local dense cores, this result suggests that the densest regions of the clouds are further fragmented.

\subsection{Extinction}

Using Eq. (1), we studied the pixel-to-pixel correlation between visual extinction and the $\mathrm{C}^{18} \mathrm{O}(J=1-0)$ integrated intensity for selected clouds. The error estimate on the mid-IR opacities is described in Appendix B. Figure 11 shows the resulting scatter diagrams. The scaling of extinction data to $A_{\mathrm{v}}$ depends on the assumed dust emissivity model. We then denote the visual extinction scale $\alpha A_{\mathrm{v}}$, where $\alpha=1$ for the DL84 model. The result of bivariate fits of our data are displayed in Fig. 11. The errors resulting from the linear regression show that this best fit line is relatively well constrained, regardless of its adequacy, or not, to properly represent the data over the whole $A_{\mathrm{v}}$ range, of the intrinsic data dispersion and of the absolute calibration uncertainty.

We now compare our results to earlier studies of local dark clouds, based on star counts. In HCL2, CG87 inferred for $A_{\mathrm{v}}$ ranging from 1.5 to 6 :

$W\left(\mathrm{C}^{18} \mathrm{O}\right)=0.28 \pm 0.05 \cdot\left(A_{\mathrm{v}}-1.5 \pm 0.3\right) \mathrm{K} \mathrm{km} \mathrm{s}^{-1}$.

For $A_{\mathrm{v}} \leq 10$, Alves et al. (1999) found in L977:

$W\left(\mathrm{C}^{18} \mathrm{O}\right)=0.18 \pm 0.01 \cdot\left(A_{\mathrm{v}}-1.67 \pm 0.26\right) \mathrm{K} \mathrm{km} \mathrm{s}^{-1}$.(4)

These relations are overplotted on the graphs of Fig. 11. An important difference with the earlier studies is that the extinction ranges probed barely overlap. The different location and nature of the sampled clouds observed with different spatial resolutions might lead to large discrepancies. The different data sets nevertheless seem compatible. Our scatter diagrams exhibit a similar break as reported by Alves et al. (1999, see also Frerking et al. 1982; Lada et al. 1994) above $A_{\mathrm{v}} \sim 10-15 \mathrm{mag}$. In our case, the departure from the linear fit occurs at higher $A_{\mathrm{v}}$ in the range 15-25 magnitudes, which is about the sensitivity limit of the previous studies. It is interesting to note that the relations given in Eqs. (3) and (4) are not inconsistent with our few sample points at $A_{\mathrm{v}}$ below 15-20 magnitudes (e.g. $\mathrm{DF}+18.56-0.15, \mathrm{DF}+25.90-0.17)$.

As for previous properties, our clouds are not all identical and their behaviour in the $\left(W\left(\mathrm{C}^{18} \mathrm{O}\right), A_{\mathrm{v}}\right)$ plane may characterise different conditions:

1. $D F+15.05+0.09$ and $D F+18.56-0.15$ : these clouds are identified as the most opaque objects of the sample and thus suffer most from the mismatch in the extinction ranges. Nevertheless the low extinction relations (Eqs. (3) and (4)) smoothly connect to our data points and are consistent with a break at $A_{\mathrm{v}}$ around 15, similar to Alves et al. (1999) findings. Their conjecture that such a break is due to molecular depletion onto grains is validated by the Kramer et al.'s (1999) study based on rare CO isotopomers. The similar break found here reinforces our assumption of significant molecular depletion inside the IR dark clouds.

2. $D F+18.79-0.03$ and $D F+25.90-0.1 \%$ : these clouds present much more points in the extinction range of Eqs. (3) and (4). Although the samples are relatively scattered, we find that the data are nicely fitted by the relation of CG and Alves et al. (1999) within 10-30\%, which is 
Table 5. $\mathrm{H}_{2}$ Column densities averaged over a $20^{\prime \prime}$ beam, in units of $10^{22} \mathrm{~cm}^{-2}$.

\begin{tabular}{|c|c|c|c|c|c|c|c|}
\hline Source name & $N_{\mathrm{H}_{2}} \stackrel{(1)}{(\text { mid-IR })}$ & $\begin{array}{c}(\mathbf{2}) \\
N_{\mathrm{H}_{2}}(1.2 \mathrm{~mm})\end{array}$ & $\begin{array}{l}\text { Assumed } \\
T_{\text {dust }}(\mathrm{K})\end{array}$ & $\begin{array}{c}(\mathbf{3}) \\
N_{\mathrm{H}_{2}}\left(\mathrm{HC}_{3} \mathrm{~N}\right) \\
(\mathrm{LVG}+\text { size })\end{array}$ & $\begin{array}{c}\left(\mathbf{3}^{\prime}\right) \\
N_{\mathrm{H}_{2}}\left(\mathrm{C}^{18} \mathrm{O}\right) \\
(\mathrm{LVG}+\mathrm{size})\end{array}$ & $\begin{array}{c}(4) \\
N_{\mathrm{H}_{2}}\left(\mathrm{C}^{18} \mathrm{O}\right) \\
\text { (Cernicharo et al.) }\end{array}$ & $\begin{array}{c}\text { Assumed } \\
T_{\text {kin }}(\mathrm{K})\end{array}$ \\
\hline $\mathrm{DF}+09.86-0.04^{(A)}$ & $3.4 \pm 1.5$ & $6.1 \pm 1.7$ & 10 & - & $2.9 \pm 1.5$ & $1.4 \pm 0.3$ & 10 \\
\hline $\mathrm{DF}+09.86-0.04^{(B)}$ & $3.1 \pm 1.4$ & $4.8 \pm 1.7$ & 17 & - & $0.6 \pm 0.1$ & $1.1 \pm 0.2$ & 17 \\
\hline $\begin{array}{l}\mathrm{DF}+15.05+0.09^{(A)} \\
\mathrm{DF}+30.23-0.20\end{array}$ & $7.7 \pm 3.4$ & $12.6 \pm 1.7$ & 8 & - & $1.2 \pm 0.6$ & $1.6 \pm 0.3$ & 8 \\
\hline star vicinity & $5.0 \pm 1.8$ & $8.3 \pm 2.7$ & 25 & $12 \pm 6$ & $0.9 \pm 0.1$ & $4.2 \pm 0.8$ & 25 \\
\hline $\begin{array}{l}\text { filament } \\
\mathrm{DF}+31.03+0.27\end{array}$ & $8.5 \pm 3.0$ & $11.1 \pm 1.7$ & 8 & $42 \pm 28$ & $?^{(C)}$ & $2.8 \pm 0.5$ & 8 \\
\hline 1st component ${ }^{(A)}$ & - & $11.1 \pm 1.7$ & 10 & $\geq 10$ & $0.75 \pm 0.15$ & $2.0 \pm 0.4$ & 10 \\
\hline 2nd component ${ }^{(A)}$ & - & $17.7 \pm 1.7$ & 10 & $12 \pm 6$ & $3.5 \pm 1.5$ & $2.0 \pm 0.4$ & 10 \\
\hline $\mathrm{DF}+51.47-0.00^{(A)}$ & - & $7.7 \pm 1.7$ & 10 & $\geq 14$ & $1.2 \pm 0.3$ & $1.6 \pm 0.3$ & 10 \\
\hline
\end{tabular}

(A) Taken at core position.

(B) Taken in the vicinity of the upper-right star cluster seen in Fig. 4.

(C) The density could not be constrained by the LVG model.

still consistent given the uncertainty implied by the factor $\alpha$ introduced above. The break position is, again, consistent with previous results and the negative intercept in agreement with Alves et al. (1999) claim that shielding is probably not efficient enough to avoid molecular photodissociation from interstellar radiation at low visual extinctions.

3. $D F+9.86-0.04$ and $D F+30.23-0.20$ : these clouds exhibit a clear lack of points of weak $\mathrm{C}^{18} \mathrm{O}$ emission at low visual extinctions. As mentioned in previous sections, these objects are associated with several young star clusters whose radiation probably heatens the surrounding core. In $\mathrm{DF}+30.23-0.20$, several $\mathrm{OH}$ and $\mathrm{CH}_{3} \mathrm{OH}$ masers (Caswell et al. 1995) have been identified at the edge of the filament (see Fig. 3), probably tracing an even more evolved state of star-formation.

We conclude that our study extends earlier studies based on star counts in a consistent way. In particular it confirms that $\mathrm{C}^{18} \mathrm{O}$ can be used as a rough column density, and thus mass, tracer in dense dark clouds, provided corrections are made to account for progressive saturation.

\section{Conclusions}

In this paper we presented millimetre follow-up observations of Galactic infrared dark clouds discovered in the galactic ISO survey at 7 and $15 \mu \mathrm{m}$. All objects are detected in ${ }^{13} \mathrm{CO}$ and $\mathrm{C}^{18} \mathrm{O}$ and present remarkable spatial correlation with the mid-IR absorption data. We found that these clouds are not isolated but appear as the most condensed parts of quiescent GMC's 2 to $8 \mathrm{kpc}$ away from us, some of them being associated with embedded stars or clusters observed by ISO. The clouds present a variety of shapes and line profiles indicative of supersonic flows. Velocity maps exhibit structures down to the parsec size connected to larger clouds along the line of sight.
Special attention was paid to the intensity calibration of our data and a simple approximation for extended sources seen in a main+error beam pattern was developed. Although not completely correct, it is believed to provide a better estimate of the main error beam integrated intensity than the widely used main-beam brightness temperature.

In spite of a certain diversity, some common behaviours are observed in our cloud sample. We found that the $(J=2-1)$ to $(J=1-0)$ ratios of ${ }^{13} \mathrm{CO}$ and $\mathrm{C}^{18} \mathrm{O}$ were remarkably uniform within each object and that a significant amount of them match the values between 0.6 and 0.8 observed in local dark clouds. Higher ratios are observed in the other objects, indicative of a broader range of conditions.

A preliminary analysis of data obtained with temperature and density probes such as $\mathrm{HC}_{3} \mathrm{~N}$ and $\mathrm{CH}_{3} \mathrm{CCH}$ shows that the clouds are mostly cold gas and dust condensations of temperatures below $10 \mathrm{~K}$ and densities in excess of $10^{5} \mathrm{~cm}^{-3}$. In those conditions, depletion onto grains is expected to strongly affect the molecular emission, but opacity effects can so far not be completely ruled out. Column densities close to $10^{23} \mathrm{~cm}^{-2}$ are inferred from the dust absorption and emission. These clouds are in an advanced condensation stage, and some of them already contain young stars. Similar massive dark clouds are reported by Egan et al. (1998) and Carey et al. (1998) in their MSX survey of the Galactic plane: the parameters they derive are in good agreement with ours.

The darkest condensations $\left(N_{\mathrm{H}_{2}} \geq 10^{23} \mathrm{~cm}^{-2}\right)$ represent $\sim 1 \%$ of the inner Galaxy surveyed with ISO. Assuming that $\$ 80 \%$ of the population escaped detection (distance bias, confusion, ...), a wild extrapolation leads to at most $10 \%$ of the dust in the inner Galaxy trapped in these cold dense cores. This is a factor $\sim 50$ too low to 

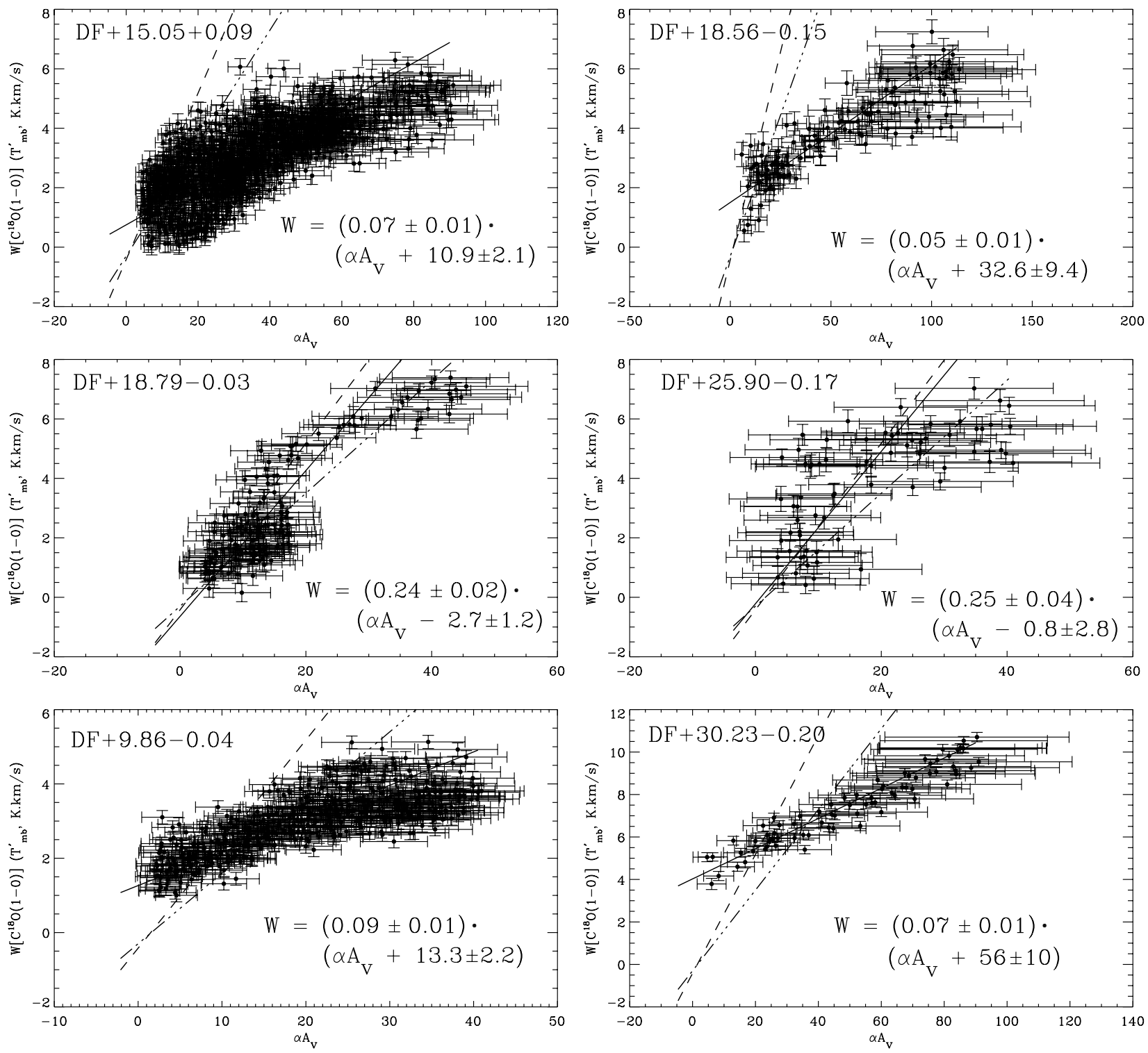

Fig. 11. Relation between the $\mathrm{C}^{18} \mathrm{O}(J=1-0)$ integrated intensity and the visual extinction derived from mid-IR measurements in six of the clouds. $\alpha$ depends on the $A_{\mathrm{v}} / A_{15 \mu \mathrm{m}}$ scaling; $\alpha=1$ for DL84. IR data were smoothed to the $\mathrm{C}^{18} \mathrm{O}$ beam size of $22^{\prime \prime}$. The error in the extinction measurements is calculated according to Eq. (B.5) while the uncertainties on $W\left(\mathrm{C}^{18} \mathrm{O}\right)$ correspond to the rms noise of the spectra. The solid line represents the least-square fit of the data weighted in both coordinates. The dashed (respectively dashed-dot-dot-dot) lines give the fits obtained for nearby dark clouds by Cernicharo \& Guélin (1987) (resp. Alves et al. 1999) and recalled in Eq. (3) (resp. Eq. (4)).

account for the hypothetical cold dust component advocated by Reach et al. (1995).

Comparison of dust mid-IR absorption and $1.2 \mathrm{~mm}$ emission points towards emissivities at $1.2 \mathrm{~mm}$ higher (factor 1.6) than Draine \& Lee (1984). On the other hand spectroscopic tracers indicate that the denser parts of the cold condensations are not volume filling, as earlier found in other situations (e.g. Lada et al. 1997).

We studied the relation between the integrated $\mathrm{C}^{18} \mathrm{O}$ emission and the visual extinction and compared it to previous results obtained for local clouds. Our study samples higher extinctions than these former studies but we find that the correlations consistently connect in the $A_{\mathrm{v}}=15$ 25 mag range and indicate that the $\mathrm{C}^{18} \mathrm{O}$ emission still is a relatively good tracer of the cloud mass at visual extinction above 15-20 magnitudes, provided corrections are made to account for radiative transfer saturation and/or depletion onto grains.

Acknowledgements. We thank the anonymous referee for constructive comments and suggestions that improved the paper. We also would like to thank Christoph Nieten for providing us with a modified version of the FLYPLAIT program for data reduced with the GILDAS software. D. Teyssier is very grateful to the IRAM 30-m staff for his help and assistance during his period there. We also acknowledge P. Schilke for providing his LVG code. We would like to thank J. F. Panis for the very useful discussions on temperature scaling and for making the IRAM key-project raw database available to us. F. Zagury of 
Nagoya University made the observations at the 4-m Nanten telescope.

\section{References}

Alves, J., Lada, C. J., \& Lada, E. A. 1999, ApJ, 515, 265

Bensch, F., Stutzki, J., Heithausen, A., et al. 2001a, A\&A, 365, 285

Bensch, F., Panis, J.-F., Stutzki, J., et al. 2001b, A\&A, 365, 275

Bohlin, R. C., Savage, B. D., \& Drake, J. F. 1978, ApJ, 224, 132

Broguière, D., Neri, R., \& Sievers, A. 1999, NIC Bolometer Users Guide

Burton, W. B., Elmegreen, B. G., \& Genzel, R. 1991, in The Galactic Interstellar Medium, Saas-Fee Advanced Course 21, lectures notes, Swiss-Society for Astrophysics and Astronomy

Carey, S. J., Clark, F. O., Egan, M. P., et al. 1998, ApJ, 508, 721

Carey, S. J., Feldman, P. A., Redman, R. O., et al. 2000, ApJ, $542, \mathrm{~L} 157$

Caswell, J. L., Vaile, R. A., Ellingsen, S. P., \& Norris, R. P. 1995, MNRAS, 274, 1126

Cernicharo, J., \& Guélin, M. 1987, A\&A, 176, 299

Draine, J. T., \& Lee, H. M. 1984, ApJ, 285, 89

Dupac, X., Giard, M., Bernard, J.-P., et al. 2001, ApJ, 553, 604

Egan, M. P., Shipman, R. F., Price, S. D., et al. 1998, ApJ, 494, L199

Emerson, D. T., Klein, U., \& Haslam, C. G. T. 1979, A\&A, $76,92(\mathrm{EKH})$

Emerson, D. T., \& Gräve, R. 1988, A\&A, 190, 353

Emerson, D. T., \& Payne, J. M. 1995, Multi-Feed Systems for Radio-Telescopes, PASP, 75, 332

Evans, N. J., II 1980, in Interstellar Molecules, ed. B. H. Andrew (Dordrecht: Reidel), IAU Symp., 87

Falgarone, E., Panis, J.-F., Heithausen, A., et al. 1998, A\&A, 331,669

Frerking, M. A., Langer, W. D., \& Wilson, R. W. 1982, ApJ, 262,590

Greve, A., Kramer, C., \& Wild, W. 1998, A\&AS, 133, 271

Hennebelle, P., Pérault, M., Teyssier, D., \& Ganesh, S. 2001, A\&A, 365, 598, Paper I
Kramer, C. 1997, Calibration of spectral line data at the IRAM 30-m telescope (IRAM internal report)

Kramer, C., Thum, C., \& Sievers, A. 1998, A Short Guide to Observations with the MPIfR Multi-channel Bolometer at the 30-m IRAM Radiotelescope (IRAM internal report)

Kramer, C., Alves, J., Lada, C. J., et al. 1999, A\&A, 342, 257

Kreysa, E. 1992, in ESA, Proceedings of an ESA Symposium on Photon Detectors for Space Instrumentation, 207 (SEE N94-15025 03-19)

Kutner, M. L., \& Ulich, B. L. 1981, ApJ, 250, 341

Lada, C. J., Lada, E. A., Clemens, D. P., \& Bally, J. 1994, ApJ, 429, L694

Lada, E. A., Evans, N. J. II, \& Falgarone, E. 1997, ApJ, 488, 286

Mauersberger, R., Guélin, M., Martín-Pintado, J., et al. 1989, A\&AS, 79, 217

Motte, F., Andre, P., \& Neri, R. 1998, A\&A, 336, 150

Oka, T., Hasegawa, T., Hayashi, M., et al. 1998, ApJ, 493, 730

Omont, A., Ganesh, S., Alard, C., et al. 1999, A\&A, 348, 755

Panis, J.-F. 1995, Ph.D. Dissertation

Pérault, M., Omont, A., Simon, G., et al. 1996, A\&A, 315, L165

Penzias, A. A., \& Burrus, C. A. 1973, ARA\&A, 11, 51

Pierce-Price, D., Richer, J. S., Greaves, J. S., et al. 2001, ApJ, 545, L121

Pratap, P., Dickens, J. E., Snell, R. L., et al. 1997, ApJ, 486, 862

Reach, W. T., Dwek, E., Fixsen, D. J., et al. 1995, ApJ, 451, 188

Sanders, D. B., Clemens, D. P., Scoville, N. Z., \& Solomon, P. M. 1986, ApJS, 60, 1S

Sakamoto, S., Hasegawa, T., Hayashi, M., et al. 1995, ApJS, 100,125

Teyssier, D., \& Sievers, A. 1999, A Fast-Mapping Method for Bolometer Array Observations at the IRAM 30-m Telescope (IRAM Technical report)

Teyssier, D., Pérault, M., \& Hennebelle, P. 2001b, in preparation

Ungerechts, H., Brunswig, W., Kramer, C., et al. 1999, IRAM 30-m Telescope Spectral Line On-The-Fly Mapping (IRAM report)

Wilson, T. L., \& Rood, R. 1994, ARA\&A, 32, 191 